\title{
If You are Offered the Right of First Refusal, Should You Accept? An Investigation of Contract Design
}

\section{Citation}

Grosskopf, Brit, and Alvin E. Roth. 2009. If you are offered the right of first refusal, should you accept? An investigation of contract design. Games and Economic Behavior, Special Issue in Honor of Martin Shubik 65(1): 176-204.

\section{Published Version}

doi:10.1016/j.geb.2007.10.013

\section{Permanent link}

http://nrs.harvard.edu/urn-3:HUL.InstRepos:4261988

\section{Terms of Use}

This article was downloaded from Harvard University's DASH repository, and is made available under the terms and conditions applicable to Open Access Policy Articles, as set forth at http:// nrs.harvard.edu/urn-3:HUL.InstRepos:dash.current.terms-of-use\#OAP

\section{Share Your Story}

The Harvard community has made this article openly available.

Please share how this access benefits you. Submit a story.

\section{Accessibility}




\title{
If you are offered the Right of First Refusal, Should you accept?
}

\author{
An Investigation of Contract Design*
}

\author{
Brit Grosskopf $^{\mathrm{a}}$ and Alvin E. Roth ${ }^{\mathrm{b}}$
}

June 12, 2005

${ }^{\mathrm{a}}$ Texas A\&M University

${ }^{b}$ Harvard Business School and Department of Economics, Harvard University

\begin{abstract}
Rights of first refusal are contract clauses that, recognizing the incompleteness of contracts, are intended to provide the holder of a license or lease with some protection when the contract comes to an end. The simplest right of first refusal gives the right holder the ability to act after potential competitors. However, another common implementation of a right of first refusal requires the right holder to accept or reject some offers before potential competitors are given the same offer, and, if the right holder rejects the initial offer, allows the right to be exercised affirmatively only if competitors are subsequently offered a better deal (e.g. a lower price).

We explore, theoretically and experimentally, the impact this latter form of right of first refusal can have on the outcome of a negotiation. We show that, counterintuitively, the "right" embodied in this form of right of first refusal can work to the disadvantage of its holder. This suggests that applied contract design may benefit from the same kind of attention to detail that has begun to be given to practical market design.
\end{abstract}

JEL classification: C78, C91, K12

Keywords: Contract design, Right of First Refusal, Bargaining experiments

\footnotetext{
${ }^{*}$ We thank Oliver Hart, Rajiv Sarin and Guhan Subramanian for several very helpful discussions. This paper has also benefited from comments of seminar participants at the Stockholm School of Economics, Columbia and Texas A\&M. The experimental interface was programmed in z-Tree, experimental software authored by Urs Fischbacher at the University of Zurich, Institute for Empirical Research in Economics, Switzerland.
} 


\section{Introduction}

In January 2001, Paramount Studios and the National Broadcasting Company (NBC) had to renegotiate the broadcasting rights for the successful television show Frasier, after the term of the original agreement expired. NBC, as the incumbent network, had a Right of First Refusal as described in the following letter of January 23, 2001 from NBC to Paramount (Subramanian, 2001a, Exhibit 1):

\footnotetext{
"This will confirm that our exclusive negotiation period will commence February 1, 2001. In order to confirm that we are both on the exact same page with respect to the negotiations for the renewal of 'FRASIER,' I am sending you this summary of the terms.
}

1. The first negotiation period lasts from February 1, 2001 to March 1, 2001. Both NBC and [Paramount] acknowledge that this negotiation period was not affected by any previous exploratory discussions (as confirmed in my fully-executed letter to you dated November 29, 2000).

2. If there is no agreement reached by March 1, 2001, Paramount will submit its last offer ('Last Offer') to NBC. If NBC rejects said Last Offer, Paramount is free to negotiate with third parties, subject to the matching rights of NBC set forth below.

3. If Paramount wants to license the series to a third party (including, without limitation, CBS), on financial terms less favorable to Paramount than the Last Offer, NBC has 10 days to match such terms. On the other hand, Paramount is free to license the show to a third party (including, without limitation, CBS) on financial terms equal to or more favorable than the last offer, without any further obligation to NBC.

4. If NBC's right to match an offer comes into play, NBC must match the aggregate, total financial value of the third party offer within 10 days of NBC's receipt of notice of the third party offer. Such financial value would include, without limitation, terms such as the term of the license fee, the number of episodes ordered, and any sharing of any revenue streams.

5. NBC's matching right continues until March 1, 2002.

The above reflects our understanding of the agreement, and we are proceeding in reliance thereon."

Note the order of events in this right of first refusal, as captured in paragraphs 2 and 3 above. For simplicity, we will speak as if the only issue under negotiation is the price per episode that Paramount will receive. The specified order is as follows: First, Paramount negotiates with NBC. If NBC rejects Paramount's last offer, then NBC has implicitly rejected any offers at a higher price, i.e., offers that are even more favorable to 
Paramount. Paramount is therefore free to reach an agreement at the refused price or higher with another network. However, if Paramount agrees to license the show to another network at a lower price (i.e., on terms that NBC has not yet refused), then NBC can exercise its right of first refusal to renew the show on NBC at that price.

This form of the right of first refusal was once standard in entertainment contracts of this kind, but has (at least in this form) not been included in the terms of many of the most recent contracts. ${ }^{1}$ However it is not hard to find evidence suggesting that this order of events is commonly written into rights of first refusal. For example, it is found in the law governing sales of rental property in Britain, where many tenants of flats in England and Wales have the right to purchase their flat before the landlord can offer it to anyone else. The Landlord and Tenant Act of 1987 (as amended) contains a right of first refusal as follows. ${ }^{2}$

\begin{abstract}
"A landlord who wishes to dispose of property containing flats must give the qualifying tenants (mainly long leaseholders and regulated tenants) the opportunity to buy it and must tell them the price and other principal terms on which they are prepared to do so. ... If the tenants do not accept the offer, the landlord can (in most cases) sell to anyone within a 12-month period provided that they offer the same interest on the same terms and at no lower price than the offer rejected by the tenants. If the landlord wishes to sell at a lower price or on different terms, they must first offer the property again to the tenants."
\end{abstract}

That is, British tenants too must exercise their right of first refusal at a price of the landlords' choosing before the property is offered to a third party, while retaining the right to exercise the right at lower prices until afterwards. We will call such a right a Before and After Right of First Refusal (BA-ROFR) to contrast it with a Last Right of First Refusal in which the right holder acts last (L-ROFR) or with a right of first opportunity in which the right holder always makes a decision before a third party. The Office of the Deputy Prime Minister states on their webpage that the British legislation implementing this BA-ROFR "strengthened the rights of leaseholders of privately owned

\footnotetext{
${ }^{1}$ Subramanian (2001a), and personal communication. There have been large changes in the organization of the industry that may account for this. As of 1993 networks were no longer legally constrained not to produce their own material, which resulted in an increase in in-house production. While networks moved upstream, studios started moving downstream by creating their own networks (e.g., Warner Brothers and Fox created WB, Paramount studios and United Television created United Paramount Network, UPN). Moreover, massive consolidations were seen in the 90's, for example Walt Disney Co. bought ABC, News Corp. acquired Fox Broadcasting, and Viacom bought CBS.

${ }^{2}$ See http://www.housing.odpm.gov.uk/order/refusal/02.htm.
} 
blocks of flats." This suggests that the BA-ROFR was implemented with the intention of helping the right holders.

Interestingly, British housing law regards this form of BA-ROFR as interchangeable with a L-ROFR that can be exercised after a public auction. The regulations say "There is also a procedure for the landlord to sell their interest at public auction, whereby the tenant [the right holder] takes the place of the successful bidder." This latter implementation is a simpler (and quite common) right of first refusal, in which the right holder always makes his decision after any third parties. ${ }^{3}$

Bikhchandani, Lippman and Ryan (2005) show that when the right holder has the option to take the place of the successful bidder in an auction, the right is beneficial to its holder. The intuition in an ascending bid auction is that, in the absence of the right, the right holder would just be an ordinary bidder, and would win the asset only if he had the highest value of all the bidders, and would pay the second highest value. However, the right of first refusal in this case allows him to stay out of the bidding and claim the asset at the auction price whenever he has the first or second highest value (in which case the auction price will be the third highest value). Notice that this form of the right of first refusal (a L-ROFR) gives the right holder an unambiguous benefit, at the cost of efficiency (and of seller revenue) since the asset is sold at the third highest price, and doesn't always go to the bidder with the highest value. ${ }^{4}$

We show below, first theoretically and then experimentally, that the situation is different when the right of first refusal is implemented as a Before and After right (BAROFR), in which the right holder must refuse some offers which can then be offered to a potential competitor, while the right holder retains the right to match better offers. We will see how such a "right" can work to the holder's disadvantage. The intuition is simple: the presence of this right allows the owner of the asset to first offer the asset to the right holder at a relatively high price $p$, and, if this price is rejected, to present an ultimatum to the third party, since the third party can buy the asset for price $p$, but any

\footnotetext{
${ }^{3}$ For example, French national institutions have a L-ROFR, as described in connection with the recent sale of the private collection of the Surrealist painter André Breton (Gilsdorf, 2003): "Preemption is a unique feature of French art auctions. At the end of a sale, federally owned institutions like the Pompidou may match any final bid and claim the work for the state, depriving some collector of a hard-fought artistic trophy."
} 
lower price will trigger the exercise of the right. The fact that the presence of the right strengthens the bargaining position of the asset owner when bargaining with third parties (who do not hold the right) also strengthens the position of the owner when he bargains with the right holder.

After exploring this property in a simple environment in which efficiency is not an issue, we will then turn to a richer environment in which we will see that this more complex right of first refusal (BA-ROFR) in fact enhances efficiency. This is in contrast to the right that allows the right holder to replace the high bidder (L-ROFR).

In the conclusion, we reflect on the use of theory and experiments in investigations of contract design. While rights of first refusal are of interest in their own right, our results suggest that contract design is likely to require the same attention to detail as market design as it moves from theory to application in the emerging area of design economics. ${ }^{5}$

\section{Modeling the Before and After Right of First Refusal: Ultimatum and Reverse Ultimatum Games}

Unless otherwise specified, the right of first refusal we speak of in the following sections will always be a before and after right, and hence, for brevity, we will sometimes speak of it simply as a Right of First Refusal (ROFR), rather than as a BA-ROFR.

Although the contract between Paramount and NBC (and the British Tenant Law) clearly lays out how and when the right of first refusal can be exercised, it does not otherwise attempt to impose a structure on how negotiations should be conducted, except to indicate that (at least in some parts of the negotiations) offers are made by the studio to the network (by the landlord to the tenants). Thus an equilibrium analysis of the ROFR within the framework of a formally specified game must make some necessarily arbitrary assumptions about the details of negotiations. To avoid reaching a conclusion about the

\footnotetext{
${ }^{4}$ Efficiency is hurt even further if the existence of a buyer who holds a L-ROFR leads other potential bidders to stay away from the auction, as it might when bidding is costly.

${ }^{5}$ See Roth (2002), Wilson (2002), and Milgrom (2004) for discussions of market design, and e.g. Abdulkadiroğlu et al. (2005), Niederle and Roth (2005), and Roth et al. $(2004,2005)$ for discussions of recent design efforts.
} 
ROFR that depends on these arbitrary assumptions, we therefore conduct the analysis in terms of two bargaining games, the ultimatum game, and the reverse ultimatum game, described in detail below. In both of these games the studio will make offers to the network(s). But when the incumbent network does not have a ROFR, the perfect equilibrium prediction is that in the ultimatum game the studio will receive almost all of the revenues to be divided, and in the reverse ultimatum game the incumbent network will receive almost all the revenues. That is, when the network does not hold a ROFR, the perfect equilibrium predictions are that the network will do poorly if negotiations are conducted as in the ultimatum game, and well if they are conducted as in the reverse ultimatum game. Thus a parallel analysis of the effect of adding a ROFR to each game offers an opportunity to investigate its effect both in negotiation environments that are favorable to the network, and in environments that are not. ${ }^{6}$ Analysis of the perfect equilibria of these games will reveal that giving the network a ROFR does not help it when it is predicted to do poorly without the right, and hurts it when it is predicted to do well without the right. ${ }^{7}$ We will then see in an experiment that although the perfect equilibrium predictions do not do well as point predictions for the outcome of play, they successfully predict the direction in which the ROFR changes the outcomes.

To concentrate on the question of whether the ROFR is beneficial to its holder, we look first at environments in which efficiency issues do not arise.

\footnotetext{
${ }^{6}$ We have abstracted away from many issues of practical importance in bargaining, not least of which is the timing of transactions (an issue explored in this kind of bargaining by Gneezy et al. 2003). We are certainly not claiming here that timing issues are unimportant; for example in the British Landlord and Tenant Act, the process of making an offer to the tenants can last over four months. However, how a BAROFR can be harmful to the right holder can be seen most clearly by looking at bargaining, with or without this right, in the absence of other complications.

${ }^{7}$ Recently, attention has been given to models that better reflect the experimental evidence that ultimatum game outcomes robustly tend to be much nearer to even divisions than simple perfect equilibrium (in own payoffs) predicts, even when stakes are high (e.g.. Roth et al. 1991, Slonim and Roth 1995). Some of these models incorporate concerns for fairness and inequality in the formulation of an individual's utility, but retain the perfect equilibrium hypothesis (see e.g. Bolton and Ockenfels, 2000 or Fehr and Schmidt, 1999). Other models relax the equilibrium assumption and focus instead on boundedly rational learning (e.g. Erev and Roth, 1995). It appears that both of these formulations would retain the qualitative characteristics that we explore here. We will return to them briefly in our discussion of the data.
} 


\section{The ultimatum and reverse ultimatum games}

For each of the two games described below, we consider bargaining by one proposer (the asset owner) and two responders (the potential buyers), and investigate the effect of giving the ROFR to the first responder. In each game, the proposer will have to divide 25 tokens. The proposer first proposes a division to the first responder, and, if no agreement is reached, then makes a proposal to the second responder. Any agreement will be between the proposer and one responder, i.e., the feasible agreements of the game are vectors of the form $(p, r 1,0)$ or $\left(p^{\prime}, 0, r 2\right)$ where $p$ or $p^{\prime}$ (the proposer's share) can be thought of as the negotiated price of the asset and $r 1$ and $r 2$ (first and second responders' potential shares) are all positive integers, and $p+r l=25=p^{\prime}+r 2$. In the event that no agreement is reached, all three players receive 0 (but a successful agreement gives a positive payment to both parties to the agreement ${ }^{8}$ ). The rules for making proposals and reaching agreements differ between the two games as described next.

The ultimatum game with one responder: The ultimatum game has been widely studied in the laboratory since the experiment of Güth, Schmittberger, and Schwarze (1982). In the two-person version (which will arise as a subgame of our three person game), one proposer makes a single proposal to one responder over how to divide a fixed sum. If the responder accepts, both players receive the proposed payoffs, and if the responder declines, both players receive 0 . In our discretized version with strictly positive proposals, the unique subgame perfect equilibrium of this game is for the proposer to propose the division $(p, r 2)=(24,1)$, and for the responder to accept, so that the proposer receives almost all of the available wealth.

The ultimatum game with two responders (and no ROFR): In the ultimatum game with two responders and no ROFR, the proposer first proposes a division $(p, r 1,0)$ to the first responder. If the first responder accepts, this is the result of the game. If the first responder declines, then the first responder receives 0 for the game, and the proposer now

\footnotetext{
${ }^{8}$ By making all feasible offers positive, we simplify the analysis at some points by avoiding indifference (between a zero payoff at agreement, and disagreement) that could lead to multiple equilibria.
} 
makes an offer to the second responder $\left(p^{\prime}, 0, r_{2}\right)$, who accepts or declines as in the twoperson ultimatum game. If the second responder rejects the offer, all players receive 0 .

This game has many Nash equilibria, but only one subgame perfect equilibrium, at which the proposer proposes $(24,1,0)$ to the first responder, who accepts. Off the equilibrium path, the first responder accepts any offer made by the proposer, and if the first responder rejects the proposer's offer, the proposer proposes $(24,0,1)$ to the second responder, who accepts any offer.

The ultimatum game with two responders and ROFR: Now consider the ultimatum game in which the first responder has the Right of First Refusal. The rules of this game are that the proposer first proposes a division $(p, r l, 0)$ to the first responder. If the first responder accepts, this is the outcome. If the first responder declines, the proposer now makes an offer $\left(p^{\prime}, 0, r 2\right)$ to the second responder. If the second responder rejects the offer, then all players receive 0 . However, if the second responder accepts the offer, the outcome depends on whether the ROFR is activated or not. If $p^{\prime} \geq p$ (i.e., if $r 2 \leq r l$ ) then the ROFR is not activated (as the first responder has already rejected price $p$ ), and the proposer receives $p^{\prime}$, the second responder receives $r 2$, and the first responder receives 0 . However if $p^{\prime}<p$ (i.e., if $r 2>r 1$ ) then, following the second responder's acceptance, the ROFR is activated, and the decision returns to the first responder. If the first responder now accepts the offer, the outcome is $\left(p^{\prime}, r 2,0\right)$, i.e., the first responder receives $r 2$, the payoff originally offered to the second responder, and the second responder receives 0 . Only if the first responder declines is the outcome $\left(p^{\prime}, 0, r 2\right)$, i.e., only in this case can the second responder receive $r 2>r 1$.

Although the ROFR changes the two responder ultimatum game from one in which the first responder is only called upon for one decision to a game in which he may be called upon for two decisions, it does not change the payoffs at a subgame perfect equilibrium. That is, we have the following result.

Theorem 1: The unique subgame perfect equilibrium payoff of the one-proposer two-responder ultimatum game with ROFR is $(24,1,0)$, i.e., it is the same as the unique subgame perfect equilibrium payoff of the game without ROFR. 
Sketch of proof: First consider the unique subgame perfect equilibrium for the one-proposer two-responder ultimatum game without the ROFR. Suppose the first responder rejects the offer $(p, r l, 0)$, with $p+r l=25$. The proposer then makes a take-itor-leave it offer to the second responder. As with the standard two-person ultimatum game, the second responder will accept any positive offer. The proposer therefore offers the smallest feasible offer to the second responder, $(24,0,1)$, which will be accepted. So, at the outset of the game, the proposer offers $(24,1,0)$ to the first responder, knowing that if the first responder rejects, the second will accept $(24,0,1)$. The first responder will accept, since otherwise he will get zero. The introduction of the ROFR does not change the subgame perfect equilibrium predictions, since at the subgame perfect equilibrium the right will never be activated. The proposer is therefore in the same situation as in the two-player ultimatum game, and never offers more than the minimum feasible amount of $l$ token to the first responder in the ultimatum game with and without the ROFR.

Of course, the well known experimental result for ultimatum games, to which we will return shortly, is that observed outcomes are, robustly, far from the perfect equilibrium, as small offers tend to be rejected (see e.g. Roth et al. 1991 or the survey of Roth, 1995).

The reverse ultimatum game with one responder: The reverse ultimatum game (RUG) was first proposed and studied experimentally by Gneezy, Haruvy, and Roth (2003). In the two-person version (which will arise as a subgame of our three person game), one proposer plays with one responder. The proposer proposes a division of the 25 tokens to the responder. If the responder accepts, then the game ends with this division as the outcome. If the responder rejects the offer, the proposer is then allowed to make another offer, as long as that offer is strictly higher by a minimum increment ( 1 token), and as long as both players' proposed shares remain strictly positive. In addition, the proposer may end the bargaining at any point, in which case both players receive 0 . That is, the game ends either when the responder accepts a proposal, or when, following a 
rejection, the proposer declines to make a better offer. ${ }^{9}$ Gneezy et al. observe that the unique subgame perfect equilibrium division for this game is $(1,24)$, i.e., the reverse of the two-player ultimatum game. The argument is straightforward: after any rejection by the responder, the proposer is left with the choice of making a better offer (and eventually receiving a payoff of at least 1), or ending the game and receiving 0 .

The reverse ultimatum game with two responders (and no ROFR): In the reverse ultimatum game with two responders and no ROFR, the proposer first proposes a division $(p, r 1,0)$ to the first responder. If the first responder accepts, this is the result of the game, and if the first responder rejects, then the proposer either makes a new offer (with strictly smaller $p$ and higher $r 1$ ), or decides to terminate bargaining with the first responder (in which case the first responder receives 0 for the game), and makes an initial offer to the second responder. This subgame now proceeds as a two-player reverse ultimatum game between the proposer and the second responder, i.e., the initial offer to the second responder $(p, 0, r 2)$ may start with $p=24$ and $r 2=1$ if the proposer wishes.

Gneezy et al. observe that in this version of the two-responder reverse ultimatum game, any division between the proposer and first responder can be achieved at a subgame perfect equilibrium. This multiplicity is driven by threats of the following form: The proposer offers $(p, r 1,0)$, with $p+r 1=25$, to the first responder and "threatens" to switch immediately to the second responder if the first responder does not accept. Of course, the perfect equilibrium outcome of the subgame of bargaining with the second responder will be $(1,0,24)$. So if the proposer believes that continued bargaining with the first responder following his initial rejection will yield $(1,24,0)$, it is sequentially rational for him to carry out his threat to switch to the second responder following any rejection. Therefore, any agreement $(p, r 1,0)$ with $p+r l=25$ can occur at a subgame perfect equilibrium.

However, one can achieve uniqueness of the subgame perfect equilibrium predictions by slightly perturbing the game so that offers $(p, r 1,0)$ to the first responder must have $p \geq 2$ (i.e., $r l \leq 23$ ). Offers to the second responder continue to require only

\footnotetext{
${ }^{9}$ The game also ends if the responder rejects an offer of 24 tokens (i.e. a price of 1 token), since the proposer cannot make another offer without decreasing his own share to zero, and the rules require that all shares be positive.
} 
that $p \geq 1$ (i.e., $r 2 \leq 24$ ). The unique subgame perfect equilibrium payoff of this "perturbed" reverse ultimatum game is $(2,23,0)$. Clearly, the uniqueness is driven by the elimination of the credibility of the threat to discontinue bargaining with the first responder in order to bargain with the second responder. It is now in the interest of the proposer to strike a deal with the first responder, since that would secure him a payoff of 2 instead of the payoff of 1 that he would get from the second responder. ${ }^{10}$ Gneezy et al. conducted experiments with both perturbed and unperturbed games and found no behavioral differences. Outcomes of both games are always in the interior of the feasible agreements, never very near to the unique subgame perfect equilibrium of the perturbed game. $^{11}$

The reverse ultimatum game with two responders and ROFR: Now consider the reverse ultimatum game in which the first responder has the Right of First Refusal. The rules of this game are the same as for the unperturbed game above, except at a subgame in which the first responder has rejected a last offer of $(p, r 1,0)$, and the second responder has accepted an offer of $\left(p^{\prime}, 0, r 2\right)$ with $p^{\prime}<p$ and $r 2>r 1$, i.e., except when the second responder has accepted an offer that is more favorable than any offer the first responder had received (and rejected). In this case, the first responder's ROFR is activated, and the first responder may either accept this offer, in which case the game ends with the outcome $\left(p^{\prime}, r 2,0\right)$, or decline it, in which case the outcome is $\left(p^{\prime}, 0, r 2\right)$. In contrast to the unperturbed reverse ultimatum game with two responders and no ROFR, the (perturbed or unperturbed) game with ROFR has a unique equilibrium payoff.

Theorem 2: The unique subgame perfect equilibrium payoff of the (unperturbed) one-proposer two-responder reverse ultimatum game with ROFR is $(24,1,0)$, i.e., it is the same as the unique subgame perfect equilibrium payoff of the one-proposer tworesponder ultimatum game with and without the ROFR.

\footnotetext{
${ }^{10}$ By the same token, the uniqueness of the $(24,1)$ split in the two-player reverse ultimatum game is driven by the restriction that offers need to be strictly positive.
} 
That is, the unique subgame perfect equilibrium payoff of the reverse ultimatum game with the ROFR, $(24,1,0)$, is qualitatively the opposite of the subgame perfect equilibrium payoff of the perturbed reverse ultimatum game without the ROFR $(2,23,0)$. Or, if we consider only the unperturbed reverse ultimatum games, then the addition of the ROFR changes the perfect equilibrium prediction from a multiplicity of outcomes, some of which are very good for the first responder, to a unique outcome that is the worst possible agreement for him, and the worst of the possible perfect equilibrium outcomes in the game in which he does not have the right. The addition of the ROFR thus completely changes the perfect equilibrium prediction for the reverse ultimatum game, to the disadvantage of the first responder, the right holder.

Sketch of proof: Suppose that the proposer's last rejected offer to the first responder was $(p, r l, 0)$ with $p+r l=25$. Any offer to the second responder with $p^{\prime}<p$ (i.e., $r 2>r l$ ) would activate the right of first refusal. It cannot be in equilibrium for the first responder to reject an offer (originally made by the proposer to the second responder) that activated the right of first refusal, since then he would receive 0 . At a perfect equilibrium he will therefore always accept any offer triggered by the ROFR. The second responder would therefore reject all offers $r 2<r 1$ and accept $r 2=r 1$, the maximum offer to the second responder that does not activate the ROFR. The proposer therefore has to choose $p$ (and hence $r 1$ ) to maximize his payoff. The smallest $r l$ he can choose is 1 . Therefore the proposer proposes $(24,1,0)$ to the first responder. The first responder accepts since no subsequent offer made to the second responder at equilibrium will activate his right of first refusal, as an offer of $(24,0,1)$ would be accepted by the second responder. Therefore, since at a perfect equilibrium the first responder can never reject, the proposer is in the same situation as in the two-player ultimatum game, and never offers more than the minimum feasible offer of 1 .

In summary, the before and after ROFR is not predicted to confer any advantages upon the first responder when he holds this right, neither in the ultimatum nor in the

\footnotetext{
${ }^{11}$ However, they found that while the imposition of a deadline does not change the perfect equilibrium prediction, it moved the outcomes observed in experiments significantly closer to the perfect equilibrium outcome.
} 
reverse ultimatum games. Once again, note that there are many necessarily arbitrary elements in the way we model this ROFR. The contract specifying how the right should enter the negotiations is, of course, quite incomplete on other aspects of the negotiations. So economic investigations of contract design, such as we undertake here, need to address a range of possibilities for the incomplete parts of the contract. We deal with that here by considering two models of negotiations, the traditional ultimatum game (UG) and the reverse ultimatum game (RUG), whose perfect equilibria span the range of predicted distributions of wealth. In Section 5 we will address the case of different private valuations by the buyers to analyze the efficiency implications of the ROFR.

\section{Experimental Design}

As described in the previous section, the basic experimental setup was that of a negotiation between one proposer and two responders over the division of 25 tokens ( 1 token was worth $\$ 0.05$, and subjects were paid their accumulated profits from 20 games at the end of the experiment). The proposer first bargained with the first responder and only afterwards potentially interacted with a second responder. Each experimental session consisted of 20 rounds (one bargaining game between one proposer and potentially two responders constituted a round). Participants remained in their preassigned roles and were randomly rematched after each round. We employed a $2 \times 2$ between-subject design, in which we varied whether the first responder was assigned the ROFR or not, and whether the proposer made a take-it-or-leave-it offer to the responder(s) (traditional ultimatum game condition) or was allowed to make multiple but increasing offers (reverse ultimatum game condition) to the responder(s), see Table I.

\begin{tabular}{|l|c|c|}
\cline { 2 - 3 } \multicolumn{1}{c|}{} & $\begin{array}{c}\text { Traditional UG } \\
\text { (UG) }\end{array}$ & $\begin{array}{c}\text { Reverse UG } \\
\text { (RUG) }\end{array}$ \\
\hline Without ROFR & $\begin{array}{c}5 \text { cohorts } \\
\text { (of } 9 \text { subjects) }\end{array}$ & $\begin{array}{c}5 \text { cohorts } \\
\text { (of 9 subjects) }\end{array}$ \\
\hline With ROFR & $\begin{array}{c}5 \text { cohorts } \\
\text { (of } 9 \text { subjects) }\end{array}$ & $\begin{array}{c}5 \text { cohorts } \\
\text { (of } 9 \text { subjects) }\end{array}$ \\
\hline
\end{tabular}

Table I: $2 \times 2$ between-subject design 
In each experimental session either one or two cohorts consisting of nine subjects each (three proposers, three first responders and three second responders) participated in one of the experimental conditions. ${ }^{12}$ Participants were randomly assigned to the roles of proposer, first and second responder. ${ }^{13}$

\section{Experimental Results}

Figure 1 plots average payoffs (including disagreements) over time for the proposer in the two different ultimatum games, with and without the ROFR. As in most ultimatum bargaining experiments, outcomes do not cluster near the extreme perfect equilibrium predictions, but rather are in the interior of the payoff space.
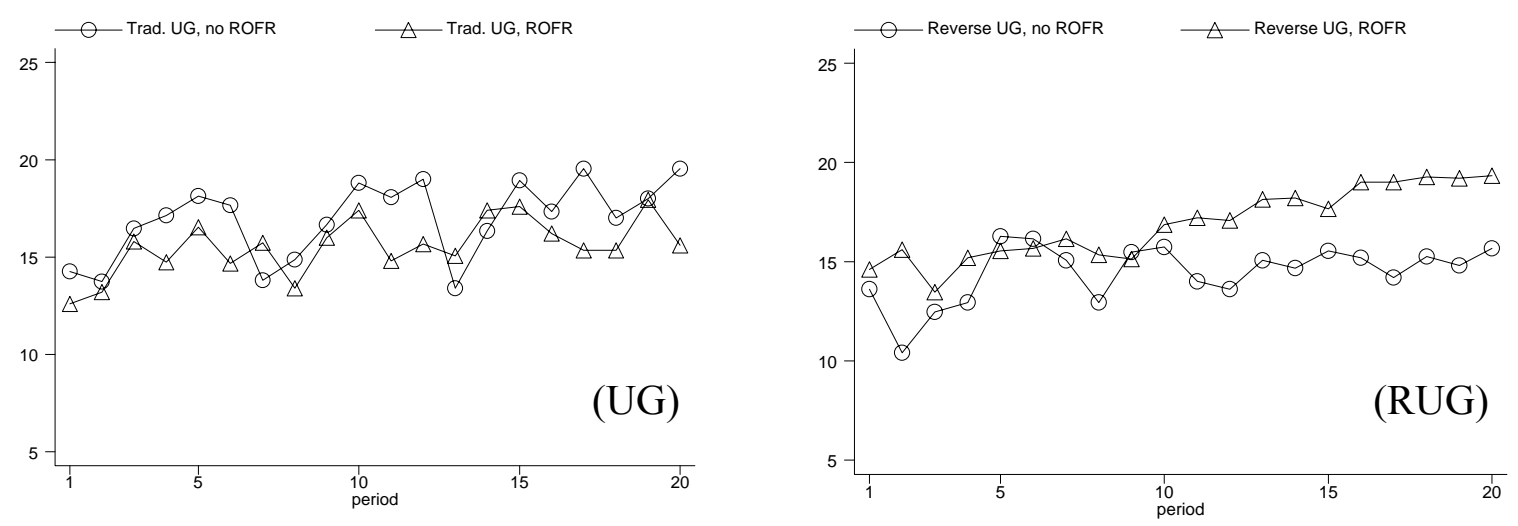

Figure 1: Average payoff of proposers over time (including disagreements), with and without the ROFR, in the traditional ultimatum game (UG), and the reverse ultimatum game (RUG)

12 While the random rematching was only done within a cohort of nine participants, subjects were not given any identification numbers, so no subject could be recognized as having been part of a particular interaction. Therefore, even though participants were matched with one another more than just once, there was no room for individual reputation building (although the repeated play aspect of the game could in principle give rise to different early-period behavior)..

13 Dividers separated the participants, who could not communicate except via the play of the game. Once seated, participants received written instructions (see Appendix B), which were also read aloud by the experiment administrator. All experimental sessions were conducted at the experimental laboratory at Harvard Business School. Participants were Greater Boston residents. The vast majority were undergraduate students from Boston University, Harvard and MIT. An experimental session lasted for about one hour with average earnings of $\$ 19$ (including a $\$ 10$ show-up fee and a potential early arrival premium of \$5), reflecting the fact that in every game at least one of the two responders earned zero. 
In both the ultimatum game and the reverse ultimatum game, the first period earnings of the proposer do not differ according to whether the ROFR was implemented or not $(12.6[\mathrm{SD}=7.02]$ vs. $14.27[\mathrm{SD}=6.08]$ in the first period of the traditional $\mathrm{UG}$, n.s., and 13.6 [SD = 5.50] vs. $14.6[\mathrm{SD}=4.70]$ in the first period of the reverse UG, n.s., Kolmogorof-Smirnov test). ${ }^{14}$ It is only over time that proposers in the reverse UG are better off when the first responder was assigned the right of first refusal. Testing payoffs in the $20^{\text {th }}$ period shows a significant difference $(19.33$ [SD $=3.12]$ vs. 15.67 [SD $\left.=3.09\right]$ $p=0.004$, Kolmogorof-Smirnov test) for the reverse UG but no significant difference for the traditional UG (15.6 [SD = 8.23] vs. 19.53 [SD = 1.96], n.s., Kolmogorof-Smirnov test). ${ }^{15,16,17}$

Figure 2 shows that the difference in the reverse UG is reflected in the lower earnings of the first responder when he is assigned the right. Testing for differences in the distribution of payoffs for the first responder in the reverse UG we find that in the first period there is no significant difference with respect to having the ROFR or not in the reverse UG (7 [SD = 7.13] vs. 7.07 [SD = 6.16], n.s., Kolmogorof-Smirnov test). The difference is significant in period $20(4.4[\mathrm{SD}=3.98]$ vs. $8.67[\mathrm{SD}=3.90], p<0.01$, Kolmogorof-Smirnov test). ${ }^{18}$

\footnotetext{
${ }^{14} \mathrm{We}$ also do robust rank order tests of the session-level data. Testing observed medians in the first round of the traditional UG with and without ROFR, the test-statistic is $\grave{U}=1.905, n s$. For the reverse UG we get, $\grave{U}=-0.088, n s$.

${ }^{15}$ The reason for this insignificance is the high variance in the traditional UG without ROFR.

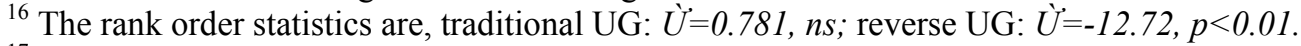

${ }^{17}$ To pin down the exact effect of the ROFR, we ran random effects censored Tobit regressions. For the specification and the exact estimation results please consult Appendix A1, Table III. There is no initial difference regarding the effect of the ROFR within each type of UG, i.e., the dummy for the ROFR is not significantly different from zero. Proposers' payoffs are increasing over time in both types of ultimatum games. This is in line with other studies that study ultimatum games with more than one responder (e.g., Grosskopf, 2003). However, proposers' profits increase significantly more over time when the ROFR is implemented, i.e., the interaction term Period*ROFR is significantly different from zero in the reverse ultimatum game but not in the traditional ultimatum game. This indicates that the strategic use of the ROFR has to be learned over time and is not immediately apparent to the participants in our experiment.

${ }^{18}$ The robust rank order statistics using the session-level data are: Traditional UG: $\dot{U}=0.211$, n.s. $\left(1^{\text {st }}\right.$

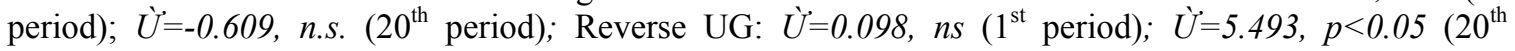
period).
} 

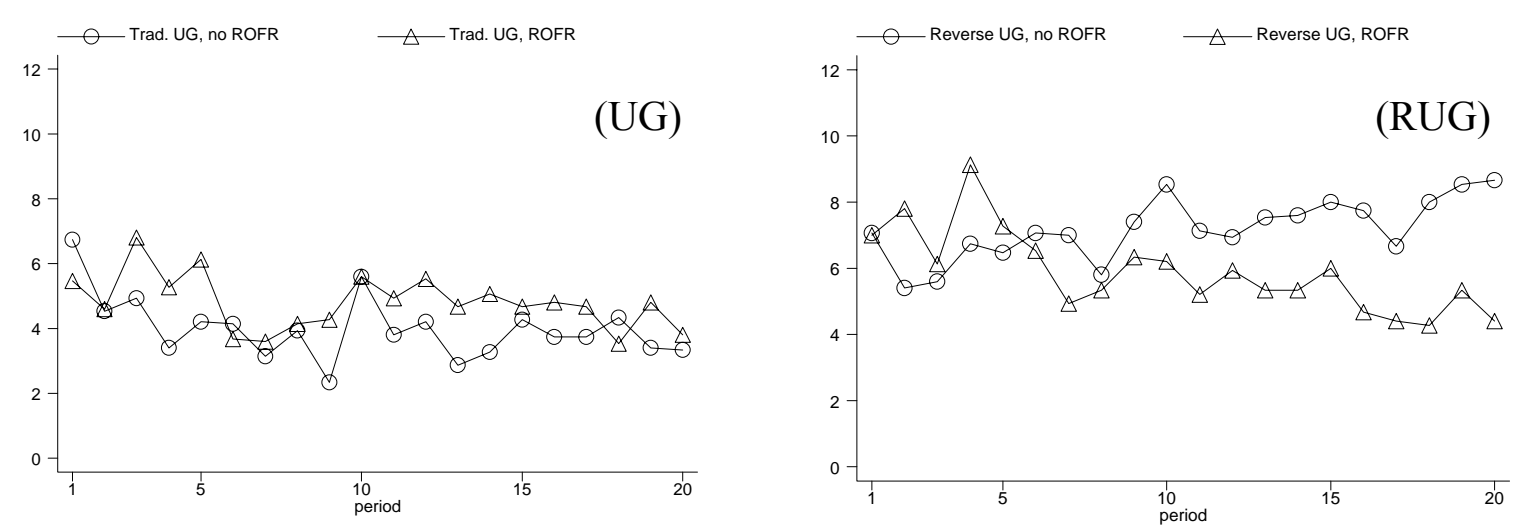

Figure 2: Average payoffs of the first responder over time (including disagreements), in the traditional UG (UG) and the reverse UG (RUG)

Figure 3 plots the average payoffs of the second responders over time in the two ultimatum games. Clearly, being the second responder is never desirable. Moreover, there is no difference in average payoffs to second responders due to the type of ultimatum game and whether the ROFR was granted. ${ }^{19}$ However, the low overall payoffs to the second responder reflect the fact that he earns zero in the majority of games, when he does not even get to play. As we can see from the dotplots in Figure 4, when the second responder does get to play in the reverse ultimatum game, he sometimes ends up with a big share of the pie in the absence of the ROFR, as suggested by the theoretical predictions for the subgame. ${ }^{20}$
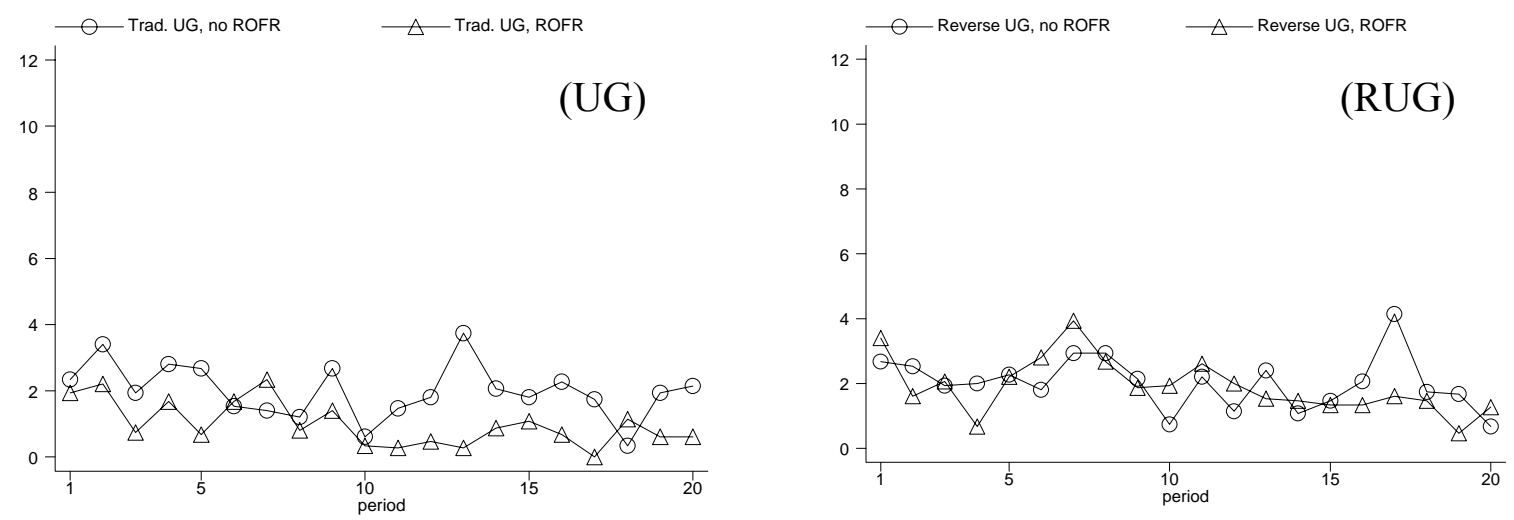

Figure 3: Average payoffs of the second responder over time, (including disagreements) in the traditional UG (UG) and the reverse UG (RUG)

\footnotetext{
${ }^{19}$ The robust rank order statistics using the session-level data are: Traditional UG: $\dot{U}=0, n s$ (1 $1^{\text {st }}$ period); $\grave{U}=-1.400$, n.s. $\left(20^{\text {th }}\right.$ period); Reverse UG: $\grave{U}=-1.170$, n.s. $\left(1^{\text {st }}\right.$ period); $\grave{U}^{\prime}=-0.988, p<0.05$ ( $20^{\text {th }}$ period).

${ }^{20}$ The dotplots plot a circle for each individual payoff. Disagreements or non-participation of the second responder result in a zero payoff.
} 
We see that 21 times (out of 69 times when he got to play) in the reverse UG without the ROFR the second responder received more than $50 \%$ of the pie, as indicated by the dots above the horizontal line. There is not a single case of a second responder receiving more than $50 \%$ of the pie in the reverse UG with the ROFR, even though the second responder got to play significantly more often in the reverse UG with the ROFR $(38.67 \%$ vs. $23 \%)$.
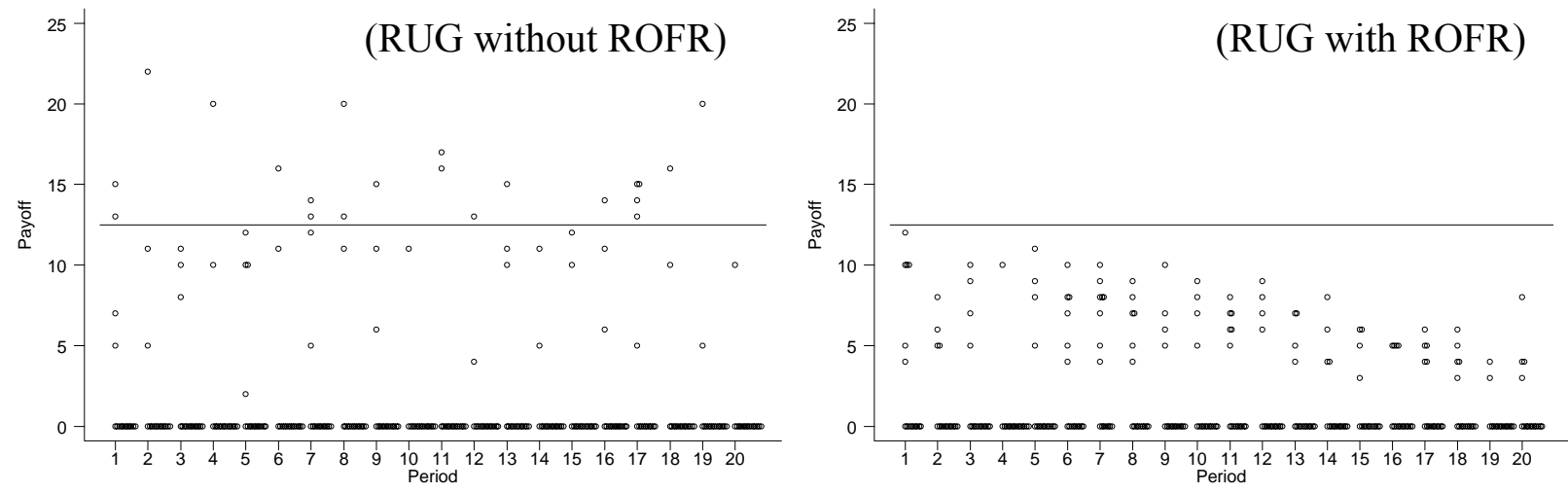

Figure 4: Dotplots of payoffs of second responders in the reverse UG

In the traditional UG, in contrast, Figure 5 shows that there is no difference in the payoff of the second responder with respect to the presence of the ROFR. The second responder never receives more than $50 \%$ of the pie in either condition.
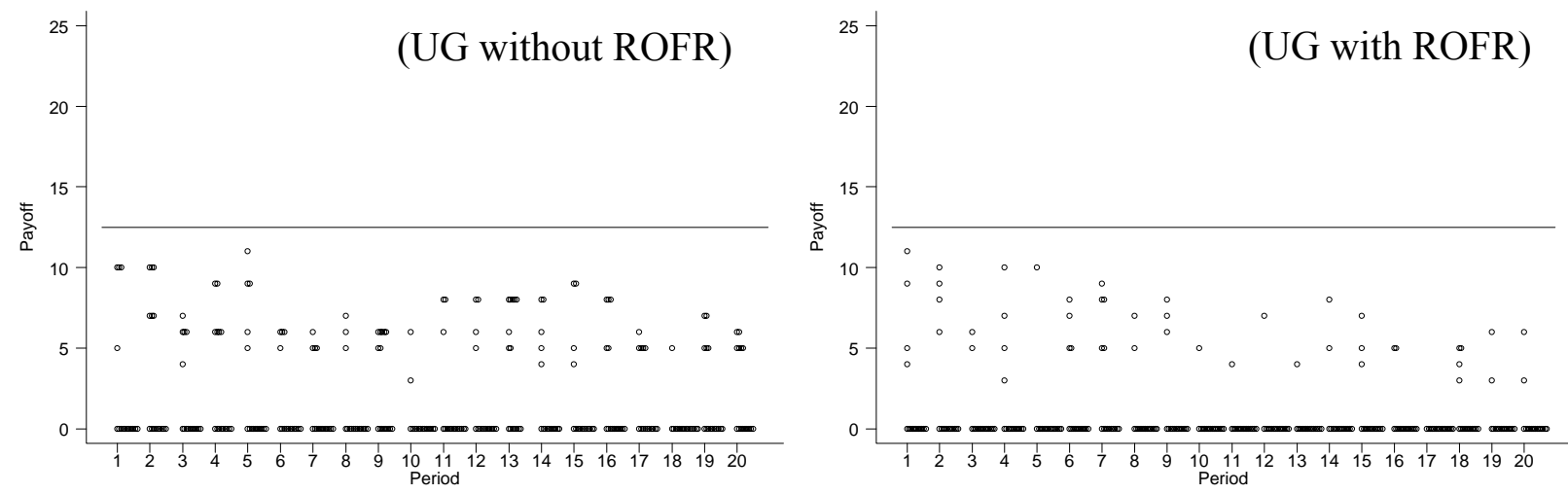

Figure 5: Dotplots of payoffs of second responders in the traditional UG 
Figures 6 and 7 show how proposers incorporated their experience with second responders into their (final) offers to first responders. Conditional on the second responder getting to play, the figures plot the first responder's last rejected offer $(R l)$ before the proposer switched to the second responder. ${ }^{21}$
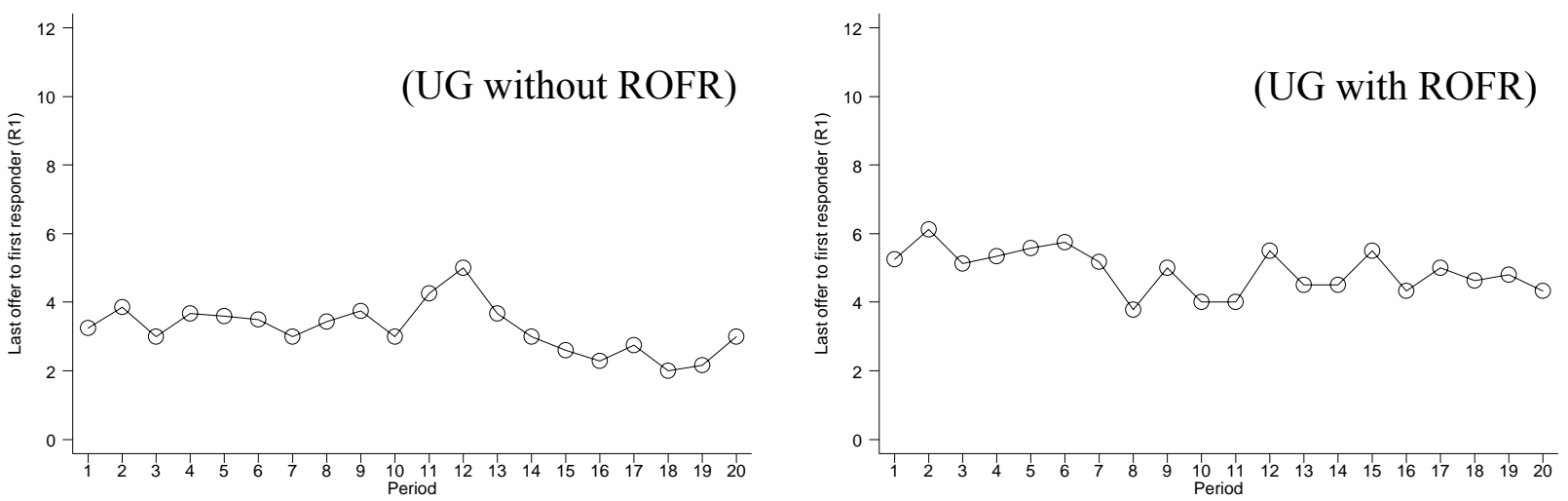

Figure 6: First responders' average rejected offer $(R 1)$ before proposer made a new offer to the second responder in the traditional UG

In the traditional ultimatum games, the introduction of the ROFR has little effect on the evolution over time of proposers" "walk away" offers, Rl (see Figure 6). However after the ROFR is introduced in the reverse ultimatum games, the right graph of Figure 7 shows that proposers become increasingly willing to walk away from the first responder, and do so at steadily lower final offers. This indicates that proposers learn the strategic use of the ROFR, i.e., over time proposers realize that it is in their power to decrease $R 1$ because the ROFR of the first responder increases their bargaining power with the second responder.

\footnotetext{
${ }^{21}$ Appendix A6 shows that the second responder's participation in the reverse UG with ROFR does not change over time. Proposers in the reverse UG without ROFR on the other hand, switch less to the second responder over time.
} 

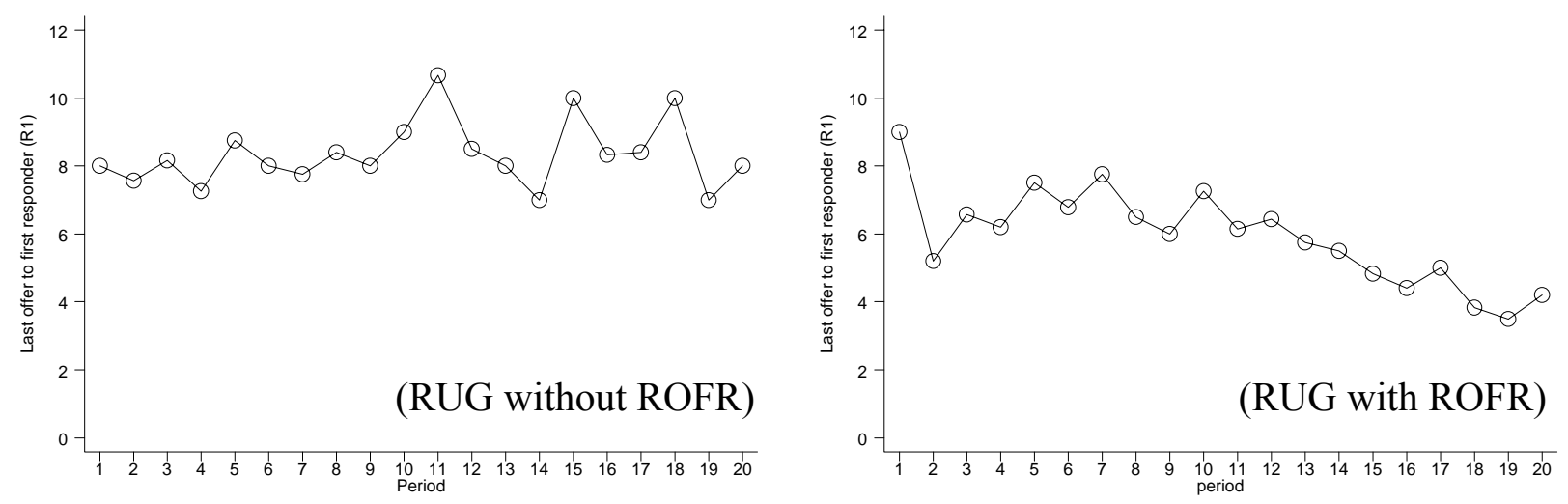

Figure 7: First responders' average last rejected offer $(R l)$ before proposer decided to switch to second responder in the reverse UG

Table II looks at the strategic aspects of this decision more closely, by tabulating the offers made to the second responder as a function of the final offer, $R 1$, made to the first responder. For each of the experimental conditions, Table II shows how the final offers accepted or rejected by the second responder compare to the final offer rejected by the first responder. This table makes clear that, in both the ultimatum game and the reverse ultimatum game, giving the first responder a ROFR induces the proposer to make fewer offers to the second responder that are more generous than his final offer to the first responder. That is, when there is no ROFR, the majority of (final) offers to second responders are more generous than the last offers made to first responders. But when the first responder has a ROFR, such offers would trigger his right. Hence, the first responder's ROFR strengthens the proposer's bargaining position with respect to the second responder, and Table II allows us to see how this plays out. ${ }^{22}$

\footnotetext{
${ }^{22}$ Note that the data shown in Table II refer to accumulated counts over all rounds and all sessions. These data are therefore not independent. We chose to report them here to better illustrate the dynamics of the bargaining process. We do not conduct any tests on these data. All statistical tests done in this paper are on independent observations, either session level data or clustered individual data.
} 


\begin{tabular}{|c|c|c|c|c|c|c|c|c|c|c|}
\hline & \multicolumn{5}{|c|}{ Traditional UG } & \multicolumn{5}{|c|}{ Reverse UG } \\
\hline & $\begin{array}{l}2^{\text {nd }} \text { got } \\
\text { to play }\end{array}$ & & \# & accepted & rejected & $\begin{array}{l}2^{\text {nd }} \text { got } \\
\text { to play }\end{array}$ & & $\#$ & accepted & rejected $* *$ \\
\hline \multirow{3}{*}{$\begin{array}{c}\text { No } \\
\text { ROFR }\end{array}$} & \multirow{3}{*}{$\begin{array}{c}38 \% \\
(114 / 300)\end{array}$} & $<R l$ & $\begin{array}{l}0.01 \% \\
(1 / 114)\end{array}$ & $\begin{array}{c}100 \% \\
(1 / 1)\end{array}$ & 0 & \multirow{3}{*}{$\begin{array}{c}23 \% \\
(69 / 300)\end{array}$} & $<R l$ & $\begin{array}{c}5.80 \% \\
(4 / 69)\end{array}$ & $\begin{array}{c}100 \% \\
(4 / 4)\end{array}$ & 0 \\
\hline & & $=R 1$ & $\begin{array}{l}18.42 \% \\
(21 / 114) \\
\end{array}$ & $\begin{array}{c}76.19 \% \\
(16 / 21) \\
\end{array}$ & $\begin{array}{c}23.81 \% \\
(5 / 21)\end{array}$ & & $=R 1$ & $\begin{array}{c}4.35 \% \\
(3 / 69) \\
\end{array}$ & $\begin{array}{c}66.67 \% \\
(2 / 3)\end{array}$ & $\begin{array}{c}33.33 \% \\
(1 / 3)\end{array}$ \\
\hline & & $>R 1$ & $\begin{array}{r}\mathbf{8 0 . 7 0 \%} \\
(92 / 114) \\
\end{array}$ & $\begin{array}{c}80.43 \% \\
(74 / 92) \\
\end{array}$ & $\begin{array}{c}19.57 \% \\
(18 / 92) \\
\end{array}$ & & $>R l$ & $\begin{array}{c}\mathbf{8 9 . 8 6 \%} \\
(62 / 69) \\
\end{array}$ & $\begin{array}{c}75.81 \% \\
(47 / 62) \\
\end{array}$ & $\begin{array}{c}24.19 \% \\
(15 / 62) \\
\end{array}$ \\
\hline \multirow{3}{*}{ ROFR } & \multirow{3}{*}{$\begin{array}{l}47.33 \% \\
(142 / 300)\end{array}$} & $<R 1$ & $\begin{array}{l}6.34 \% \\
(9 / 142) \\
\end{array}$ & $\begin{array}{c}66.67 \% \\
(6 / 9)\end{array}$ & $\begin{array}{c}33.33 \% \\
(3 / 9)\end{array}$ & \multirow{3}{*}{$\begin{array}{l}38.67 \% \\
(116 / 300)\end{array}$} & $<R l$ & $\begin{array}{l}4.31 \% \\
(5 / 116) \\
\end{array}$ & $\begin{array}{c}100 \% \\
(5 / 5)\end{array}$ & 0 \\
\hline & & $=R 1$ & $\begin{array}{l}36.62 \% \\
(52 / 142) \\
\end{array}$ & $\begin{array}{c}80.77 \% \\
(42 / 52) \\
\end{array}$ & $\begin{array}{c}19.23 \% \\
(10 / 52)\end{array}$ & & $=R 1$ & $\begin{array}{c}\mathbf{6 8 . 9 7 \%} \\
(80 / 116) \\
\end{array}$ & $\begin{array}{r}100 \% \\
(76 / 76) \\
\end{array}$ & 0 \\
\hline & & $>R I$ & $\begin{array}{c}57.04 \% * \\
(81 / 142)\end{array}$ & $\begin{array}{c}61.73 \% \\
(50 / 81) \\
\end{array}$ & $\begin{array}{c}38.27 \% \\
(31 / 81) \\
\end{array}$ & & $>R l$ & $\begin{array}{c}26.72 \% * \\
(31 / 116) \ddagger\end{array}$ & $\begin{array}{c}74.19 \% \\
(23 / 31) \\
\end{array}$ & $\begin{array}{c}25.81 \% \\
(8 / 31) \\
\end{array}$ \\
\hline
\end{tabular}

Note: *In all of those cases the ROFR was invoked and the first responder accepted the offer.

**Since the table lists final offers, the proposer decided to end the bargaining after each rejection tabulated here. $\$ 21$ out of those 31 times a second responder had been offered an amount equal to $R I$ before being offered more.

Table II: Observed frequencies of participation and final offers made to the second responder ( $R 1$ is the last offer rejected by the first responder and is known to the second responder. \# indicates the proportion of accepted or rejected final offers to the second responder that are smaller, equal or greater than $R l$ )

The second responder gets to play less often in the reverse ultimatum game without ROFR, $23 \%$, than in the traditional ultimatum game without ROFR, 38\%. In both ultimatum games without ROFR, the second responder then leaves the negotiation with a bigger share than that originally rejected by the first responder, $80.70 \%$ in the traditional UG and $89.86 \%$ in the reverse $\mathrm{UG}^{23}$ In the traditional UG this happens because the proposer made a higher take-it-or-leave-it offer to the second responder. This higher take-it-or-leave-it offer might have been induced by the belief that the rejection of the first responder is somehow representative of the responder population, and offering more to the second responder might increase the expected profit of the proposer by decreasing the likelihood of a rejection. In the reverse UG this happens because the second responder often rejects small offers (recall that second responders know $R 1$ ) and essentially presents the proposer with an ultimatum. In $24.19 \%$ of those

\footnotetext{
${ }^{23}$ As we have mentioned before, in 21 out of 69 of those cases, the second responder does not only get more than what was previously rejected by the first responder, but he gets more than half of the entire available pie (see the left graph in Figure 4).
} 
cases the proposer decides to end the negotiation, rather than give the second responder a still bigger share.

When the ROFR is introduced, the second responder gets to play slightly more often in the traditional UG, $47.33 \%$, than in the reverse $U G, 38.67 \%$. In both types of ultimatum game this observed participation of the second responder is higher when the ROFR is implemented compared to the situation when it is not $(47.33 \%$ vs. $38 \%$ in the traditional UG, and $38.67 \%$ vs. $23 \%$ in the reverse UG). However, the observed frequency of the second responder getting a more favorable outcome than the one rejected by the first responder is smaller when the ROFR is implemented. In the traditional UG with ROFR, the second responder got a more generous offer only 81 times out of $142(57.04 \%)$, compared to 92 out of $114(80.70 \%)$ in the traditional UG without ROFR. In the reverse UG, this difference is more pronounced. The second responder received a more favorable offer than $R 1$ in the reverse UG with the ROFR only 31 out of 116 times $(26.72 \%)$, compared to 62 out of 69 times $(89.86 \%)$ without the ROFR. Interestingly, out of the 31 "final" offers that end up being greater than $R 1$, only 10 times did the second responder not even get the chance to accept an offer equal to $R l$. In all other 21 cases the second responder had been offered an amount equal to $R l$ before being offered more. It is clear that letting the proposer offer more than $R I$ is a mistake by the second responder since once it was evoked, the first responder always exercised his right of first refusal.

Note also that $89.86 \%$ of final offers to the second responder are higher than $R l$ in the reverse UG without the ROFR, but more than $2 / 3$ of all final offers in the reverse UG with the ROFR are exactly at $R 1$, the "exercise point" of the ROFR. Thus in the subgame in which the second responder gets to play, we see behavior that conforms closely to the perfect equilibrium prediction.

In light of these data, which clearly show that the before and after ROFR is disadvantageous to its holder in the reverse ultimatum game, we can ask why it was not equally disadvantageous in the traditional ultimatum game? The perfect equilibrium prediction that the right will have no effect in the traditional ultimatum game rested on the prediction that the first responder would already be doing as badly as possible even without the right. However in the experimental environment, first responders make 
positive profits in the ultimatum game without ROFR, comparable to those they make in the reverse ultimatum game without ROFR. What then accounts for the lack of effect when the ROFR is introduced in the traditional ultimatum game?

One possibility is that subjects' preferences for fairness, or for not being treated unfairly, (as in Bolton and Ockenfels, 2000, or Fehr and Schmidt, 1999), simply change the minimal acceptable responder payoff without changing the effect of the ROFR. In this view, proposers are in fact doing about as well as they can in the ultimatum game even though responders are receiving a substantial share of the profits. The fact that observed agreements change over time could then be consistent with fully rational learning about the reservation price of the responders, or with less than fully rational learning of the kind studied e.g. in Roth and Erev (1995) and Erev and Roth (1998).
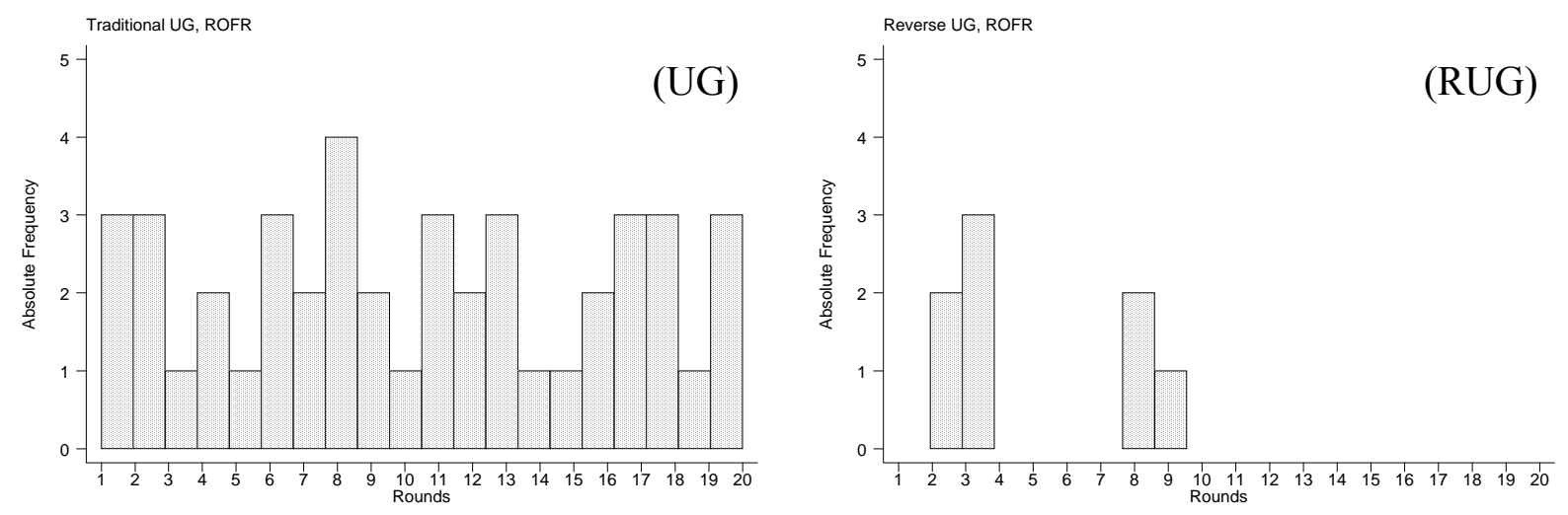

Figure 8: Histogram of disagreements in the UGs with ROFR over time

The left graph of Figure 8 shows that rejections persist over time in the ultimatum game, which is not the case in the reverse ultimatum game (see the right graph of Figure $8)^{24}$

Thus, while the experimental results differ from the perfect equilibrium predictions, the effect of the before and after ROFR that we observe in the experiments is precisely as predicted, it hurts the holder of the right in the reverse ultimatum game (in which he is predicted to do well without the right) and it does not help him in the ultimatum game (in which he is predicted to do poorly without the right).

\footnotetext{
${ }^{24}$ See Appendix A7 for a more thorough analysis of the disagreement behavior.
} 


\section{Efficiency}

So far, to make clear how the before and after right of first refusal can hurt the right holder, we have concentrated on a simple environment in which all agreements are efficient. We now consider the case in which the first responder (the right holder) and the second responder (the third party) can have different values for the asset (both higher than the seller's value). Then efficiency requires that the asset be sold to the buyer with the higher value. But if the bargaining is conducted as in the reverse ultimatum game, then the seller will only receive the lowest feasible price regardless of to whom he sells, and so he is indifferent to whom he sells, i.e., he has no preference to transact with the high value buyer. When the right holder has a BA-ROFR, however, the seller will be able to extract the entire value of the lower valued buyer, by transacting efficiently with the high value buyer. Thus the harm that the BA-ROFR does to the right holder does not come at the expense of efficiency.

Note that we will be showing that, in the bargaining environments we consider here, the BA-ROFR has exactly the opposite properties that the right to move last and replace the winning bidder has in a second price auction (L-ROFR). Whereas that kind of L-ROFR helps the right holder but reduces efficiency, here the BA-ROFR hurts the right holder but promotes efficiency. ${ }^{25}$

In order to concentrate on the effect of the right of first refusal in the starkest case, we consider a model in which the values of the buyers are common knowledge. Let $X$ be the first responder's valuation of the asset, and $Y$ be the valuation of the second responder. The reverse ultimatum game in this (variable value) environment can be described as follows: the proposer first asks for a price to be paid by the first responder. If the first responder rejects that price, the proposer can revise his asking price (decrease it by at least one token) or switch to the second responder. The proposer can ask for a new initial price to be paid by the second responder. If the second responder rejects that price, the proposer can decrease his asking price by at least one token or decide to end the bargaining altogether, in which case all players receive a payoff of zero. 


\section{Reverse UG without ROFR:}

Lemma 1: Independently of the size of $X$ and $Y$, there exist multiple subgame perfect equilibrium payoffs of the one-proposer two-responder reverse ultimatum game without ROFR. In particular, when $X<Y$ there exist inefficient equilibrium outcomes, in which the first responder is awarded the object and agrees to pay any price $p$, with $0<p$ $<X$.

Main element of the proof: The proof follows our earlier discussion of multiple equilibria, with the driving force behind the multiplicity being the indifference of the proposer between reaching an agreement of $(1, X-1,0)$ with the first responder or $(1,0, Y-1)$ with the second responder.

Because this multiplicity of equilbria is driven by the proposer's indifference between paths of play at which he receives the minimum feasible price, if we perturb the minimum price that can be feasibly offered to one of the buyers, we can get a unique subgame perfect equilibrium in a way that is independent of efficiency considerations. For example, consider a perturbed reverse ultimatum game in which the minimum price that can be asked of the first responder is $p=2$, while the minimum price that can be asked of the second responder remains $p=1$. This will induce the proposer to trade with the first responder at any subgame perfect equilibrium, regardless of whether this is efficient. That is, we have the following corollary.

Corollary: In the perturbed RUG without ROFR, independently of the size of $X$ and $Y$, the unique subgame perfect equilibrium outcome is that the first responder always

\footnotetext{
${ }^{25}$ So one can imagine an environment in which all parties understand that the right of first refusal formulated in this way is disadvantageous to the right holder, but that in the other terms of the contract the right holder is compensated for this, out of the anticipated efficiency gains that result.
} 
receives the asset and pays $p=2$. When $X<Y$, this unique equilibrium outcome is inefficient.

However, the introduction of the BA-ROFR reestablishes efficiency. We have the following results.

\section{Reverse UG with ROFR:}

Theorem 3: At any subgame perfect equilibrium of the reverse ultimatum game with BA-ROFR, the responder with the higher valuation will buy the object. A) If $X<Y$, there are two subgame perfect equilibrium prices, one in which the price is $X+1$ and one in which the price is $X$. B) If $X>Y$, then the two subgame perfect equilibrium prices are $Y$ and $Y-1$.

Sketch of the proof: A) In the subgame with the second responder, after an offer of a price $p=X+1$ to the first responder has been made and rejected, the proposer asks for $X+1$, i.e., offers $Y-(X+1)$ to the second responder, who accepts if he believes that the first responder would agree to pay a price of $X$. Since the first responder is indifferent between paying a price of $X$ and not getting the object at all, we have another equilibrium in which the second responder thinks that the first will not accept a price of $X$ and therefore is only willing to pay $X$ himself. Therefore, the second responder who values the good more, always gets the object and pays a price just above the first responder's valuation or at the first responder's valuation. Note that, while the BA-ROFR reestablishes efficiency, it clearly hurts the right holder in this case since he never earns positive profits (in contrast to the game without a right of first refusal). B) If the valuation of the right holder is higher than that of the potential outside buyer, the proposer would ask for a price of $Y$ from the first responder, who accepts, since otherwise the proposer would ask for $Y$ from the second responder who is indifferent between accepting that price and refusing it. The second responder's willingness to pay $Y$ supports an equilibrium price of $Y$. An equilibrium price of $Y-1$ is supported by the 
second responder rejecting $Y$ but accepting a price of $Y-1$. We therefore again have two equilibria, and both are efficient.

\section{Discussion}

Many economic transactions are regulated by contract, and because of the incompleteness of contracts, clauses such as rights of first refusal are intended to give one of the parties the security needed to justify fixed investment that will be lost if, at the conclusion of the contract, the asset is transferred to a third party. ${ }^{26}$ However, "before and after" rights of first refusal, found in entertainment and real estate, can work to the disadvantage of the right holder. Because they require the right holder to exercise the right before a third party for some offers, while retaining the right to take better offers after they have been proposed to the third party, they permit the asset owner to present the third party with an ultimatum, in a way that gives the asset owner an advantage, and the right holder a disadvantage, compared to the case when negotiations are conducted without such a right.

Because the entertainment contracts and rental legislation that motivate this study describe the form of the right of first refusal in detail, but are silent on other aspects of negotiation, we study the effect of the right in two, quite different negotiation environments, the traditional ultimatum game and the reverse ultimatum game. This allows us to see the effect of the right, and understand how it interacts with other aspects of negotiation, more clearly than if we confined our attention to a single negotiating environment. ${ }^{27}$ This may be an approach that will be useful more generally in analyzing aspects of contract design, since contracts are necessarily incomplete on many issues that may interact with the design features being studied.

We chose to study this contract form theoretically and experimentally for several reasons. First, field data on performance of contracts of this type are sparse and incomplete, not only in equilibrium (at which it is predicted that the ROFR is never

\footnotetext{
${ }^{26}$ See Kahn (1999) and Walker (1999) for analyses of other varieties of ROFR than those considered here.

${ }^{27}$ And, of course, rights may interact differently with different rules of bargaining.
} 
activated), but also in practice. ${ }^{28}$ And a theoretical demonstration alone would not be persuasive if it depended on the accuracy of perfect equilibrium as a point predictor, since perfect equilibrium is a notoriously bad point predictor for games of this sort. But theory and experiments are complements here, to each other, and to the sparse information from the field. Together they allow us to look inside the legal terms of a contract, and examine its effects on the parties. As in other areas of economic design, the details matter. ${ }^{29}$ In this case, simple theory suggests, and experiments confirm, that the sequencing of events in this "before and after" right of first refusal can cause it to work to the disadvantage of the right holder.

The question remains of why the BA-ROFR was implemented in the first place. One may argue that the BA-ROFR is only one part of a more complex contract, and other factors from which we have abstracted might mitigate the effect of the BA-ROFR. However, despite the efficiency enhancing properties, it seems likely that, in the entertainment industry and in the rental legislation in England and Wales, this form of right of first refusal was implemented by mistake, at least on the part of some of the parties, and has not "strengthened the rights of the leaseholders" as was intended by the legislators. Bad contract clauses can perhaps survive because of slow learning in bargaining games of this sort (see for example, Roth and Erev 1995), and because the players who do get the most opportunity to learn from repeated play, such as large landlords, may profit from this kind of right being given to tenants. ${ }^{30}$

\footnotetext{
${ }^{28}$ In the negotiations over Frasier, Paramount and NBC remained at the bargaining table after the deadline had expired and finally agreed on a price, without a formal "Last Offer" ever being issued (see Subramanian, 2001b). However non-incumbent networks occasionally do enter the negotiations, and some shows do change networks. For example, Sabrina, the Teenage Witch moved from ABC to WB in fall 2000 and Buffy, the Vampire Slayer switched from Warner Brothers (WB) to United Paramount Networks (UPN) in February 2001. Susan Laury alerted us to the latter example.

${ }^{29}$ Most experimental work so far in economic design has concerned market design (see e.g. Kagel and Roth 2000; Roth, 2002; Wilson, 2002; Milgrom, 2004), and much less has concerned contract design. But see Grether and Plott (1984) for a notable early exception (and related work by Holt and Scheffman, 1987, and Schnitzer, 1994 showing that advance price notices in combination with other contract clauses can be anticompetitive, although they appear to be designed to protect the consumer).

${ }^{30}$ Bad clauses may also be "bundled" with good ones. For example, while the right of first refusal contained in paragraphs 2 and 3 of the letter from NBC to Paramount may put NBC at a disadvantage in the subsequent bargaining, the specification in paragraph 1 that the bargaining will not begin until February 2001, may have protected NBC from bearing efficiency losses from having to negotiate the contract renewal much further in advance of its expiration date. This kind of "unraveling" is common in many twosided matching transactions (see e.g. Roth, 1984; Roth and Xing, 1994; Avery et al. 2001, Niederle and Roth, 2003, 2004, McKinney, Niederle, and Roth 2005.)
} 
Because contracts are renewed only episodically, and because individual contract clauses may be activated even more rarely, contracts may be under less "evolutionary pressure" than market rules, making it more likely that conventional contracts may contain hidden effects of the kind discussed here. It therefore seems likely that careful economic analysis at a detailed level may have as much to offer in the design and redesign of contracts as in the design and refinement of markets. 


\section{References}

Abdulkadiroğlu, Atila, Parag A. Pathak, and Alvin E. Roth, "The New York City High School Match,"American Economic Review, Papers and Proceedings, May, 2005, forthcoming.

Abdulkadiroğlu, Atila, Parag A. Pathak, Alvin E. Roth, and Tayfun Sönmez, "The Boston Public School Match," American Economic Review, Papers and Proceedings, May, 2005, forthcoming.

Avery, Christopher, Christine Jolls, Richard A. Posner, and Alvin E. Roth, "The Market for Federal Judicial Law Clerks", University of Chicago Law Review, 68, 3, Summer, 2001, 793-902.

Bikhchandani, S., S. A. Lippman and R. Ryan (2005), "On the Right-of-First-Refusal", Advances in Theoretical Economics: Vol. 5: No. 1, Article 4.

http://www.bepress.com/bejte/advances/vol5/iss1/.

Bolton, Gary E. and Axel Ockenfels [2000], "ERC: A Theory of Equity, Reciprocity and Competition, American Economic Review, 90, 1, March, 166-193.

Erev, Ido and Alvin E. Roth (1998) "Predicting how people play games: Reinforcement learning in experimental games with unique, mixed strategy equilibria," American Economic Review, 88, 4, September, 848-881.

Fehr, Ernst and Klaus Schmidt (1999), "A Theory of Fairness, Competition and Cooperation," Quarterly Journal of Economics, Vol. 114, No. 3 (1999), 817-868.

Fischbacher, U. (1999), z-Tree - Zurich Toolbox for Readymade Economic Experiments - Experimenter's Manual, mimeo. 
Gilsdorf, Ethan (2003), "Surrealism's Bittersweet End," Chronicle of Higher Education, June 13.

Gneezy, U., E. Haruvy and A.E. Roth (2003), Bargaining under a Deadline: Evidence from the Reverse Ultimatum Game, Games and Economic Behavior, 45: 347 - 368.

Grether, D.M. and C.R. Plott (1984), The Effects of Market Practices in Oligopolistic Markets: An Experimental Examination of the Ethyl Case, Economic Inquiry, 22: 479 507.

Grosskopf, B. (2003), Reinforcement and Directional Learning in the Ultimatum Game with Responder Competition, Experimental Economics, 6(2): 141 - 158.

Güth, W., R. Schmittberger and B. Schwarze (1982), An Experimental Analysis of Ultimatum Bargaining, Journal of Economic Behavior and Organization, 3: 367 - 388.

Holt, C.A. and D.T. Scheffman (1987), Facilitating Practices: The Effect of Advance Notice and Best-Price Policies, RAND Journal of Economics, 18: 187 - 197.

Kagel, John H. and A.E. Roth, "The dynamics of reorganization in matching markets: A laboratory experiment motivated by a natural experiment," Quarterly Journal of Economics, February, 2000, 201-235.

Kahn, M. (1999), An Economic Analysis of Rights of First Refusal, NYU Center for Law and Business working paper \#CLB-99-009.

McKinney, C. Nicholas, Muriel Niederle, and Alvin E. Roth, "The collapse of a medical labor clearinghouse (and why such failures are rare)," American Economic Review, June, 2005 , forthcoming.

Milgrom, P. (2004), Putting Auction Theory to Work, Cambridge University Press. 
Niederle, Muriel and Alvin E. Roth (2003), "Unraveling reduces mobility in a labor market: Gastroenterology with and without a centralized match," Journal of Political Economy, 111: 1342 - 1352.

Niederle, Muriel and Alvin E. Roth, "The Gastroenterology Fellowship Match: How it failed, and why it could succeed once again," Gastroenterology, 127, 2 August 2004, 658-666.

Niederle, Muriel and Alvin E. Roth, "The Gastroenterology Fellowship Market: Should there be a Match?," American Economic Review, Papers and Proceedings, May, 2005, forthcoming.

Roth, A.E. (1984) "The Evolution of the Labor Market for Medical Interns and Residents: A Case Study in Game Theory", Journal of Political Economy, 92, 991-1016.

Roth, A.E. (1995), Bargaining Experiments, in Kagel, J. and Roth, A.E. editors, Handbook of Experimental Economics, Princeton University Press.

Roth, A.E. (2002), The Economist as Engineer: Game Theory, Experimentation, and Computation as Tools for Design Economics, Fisher-Schultz Lecture, Econometrica, 70, 4, July, 1341-1378.

Roth, A.E. and I. Erev (1995), "Learning in Extensive-Form Games: Experimental Data and Simple Dynamic Models in the Intermediate Term," Games and Economic Behavior, 8, January, 164-212.

Roth, A.E., Prasnikar, V., Okuno-Fujiwara, M., and Zamir, S. (1991) "Bargaining and Market Behavior in Jerusalem, Ljubljana, Pittsburgh, and Tokyo: An Experimental Study," American Economic Review, 81, December, 1068-1095. 
Roth, Alvin E., Tayfun Sönmez and M. Utku Ünver, "Kidney Exchange," Quarterly Journal of Economics, 119, 2, May, 2004, 457-488.

Roth, Alvin E., Tayfun Sönmez, and M. Utku Ünver, "A Kidney Exchange Clearinghouse in New England," American Economic Review, Papers and Proceedings, May, 2005, forthcoming.

Roth, A.E. and X. Xing (1994) "Jumping the Gun: Imperfections and Institutions Related to the Timing of Market Transactions," American Economic Review, 84, September, 9921044.

Schnitzer, M. (1994), Dynamic Duopoly with Best-Price Clauses, RAND Journal of Economics, 25, 1: 186 - 196.

Slonim, R. and A.E. Roth "Learning in High Stakes Ultimatum Games: An Experiment in the Slovak Republic,"_Econometrica, 66,3, May 1998, 569-596.

Subramanian, G. (2001a), Frasier (A) (HBS Case Study 9-801-447, Rev. June 11,2001).

Subramanian, G. (2001b), Frasier (B) (HBS Case Study 9-801-448, Rev. June 11,2001).

Walker, D. I. (1999), Rethinking Rights of First Refusal, Stanford Journal of Law, Business \& Finance.

Wilson, R. (2002), “Architecture of Power Markets,” Econometrica, 70, 20, July, 12991340. 


\section{Appendix A}

\section{A1. Proposers' Payoff over Time}

We run random effects censored Tobit regressions where the lower limit is 0 and the upper limit is 24 (the maximum amount a proposer could potentially receive), separately for each type of ultimatum game, in which we regressed the profit of the proposer (profit) on a time trend (period), a dummy representing whether the ROFR (ROFR) was implemented or not and an interaction term between the periods and the ROFR (Period*ROFR). Table III shows the main results.

\begin{tabular}{||c||c|c||c|c||}
\hline \multicolumn{1}{|c|}{} & \multicolumn{2}{c|}{ Traditional UG } & \multicolumn{2}{c|}{ Reverse UG } \\
\cline { 2 - 5 } Period & Coefficients & $p>|z|$ & Coefficients & $p>|z|$ \\
\hline \hline \multirow{2}{*}{ ROFR } & $\begin{array}{c}\mathbf{0 . 1 8 7} \\
(0.0712)\end{array}$ & $\mathbf{0 . 0 0 9}$ & $\begin{array}{c}\mathbf{0 . 1 2 7} \\
(0.0451)\end{array}$ & $\mathbf{0 . 0 0 5}$ \\
\hline Period*ROFR & $\begin{array}{c}-1.112 \\
(1.2083)\end{array}$ & 0.357 & $\begin{array}{c}0.808 \\
(0.7640)\end{array}$ & 0.290 \\
\hline Constant & $\begin{array}{c}-0.051 \\
(0.1008)\end{array}$ & 0.615 & $\begin{array}{c}\mathbf{0 . 1 5 9} \\
(0.0637)\end{array}$ & $\mathbf{0 . 0 1 2}$ \\
\hline Log Likelihood & $\begin{array}{c}\mathbf{1 4 . 8 5 6} \\
(0.8530)\end{array}$ & $\mathbf{0 . 0 0 0}$ & $\begin{array}{c}\mathbf{1 2 . 9 8 7} \\
(0.6173)\end{array}$ & $\mathbf{0 . 0 0 0}$ \\
\hline
\end{tabular}

Table III: Results of the random effects censored Tobit regressions

(Standard errors are given in parentheses, numbers in bold indicate significance at $p<0.05$ ).

\section{A2. Behavior of First Responder (Traditional UG)}
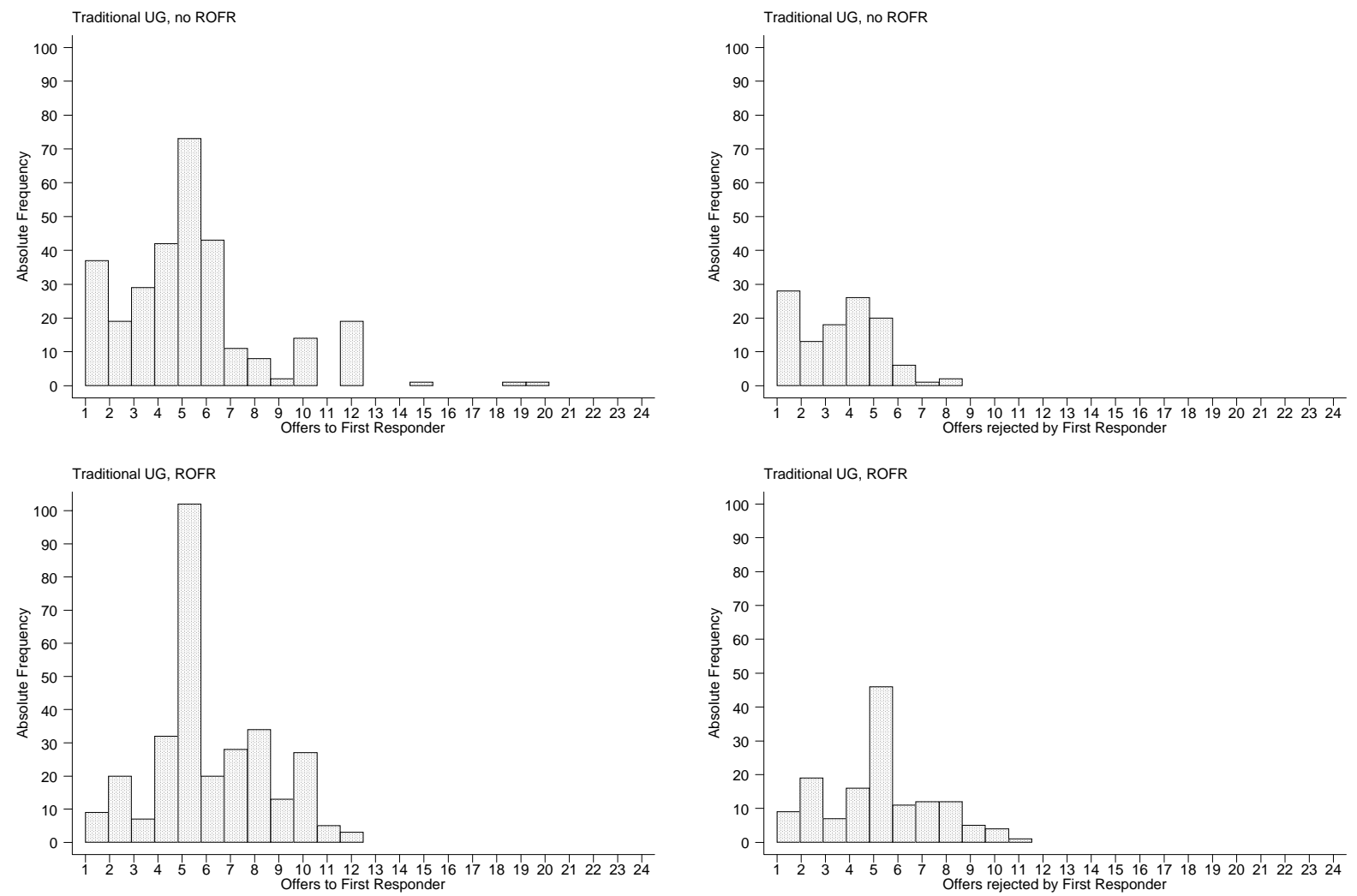

Figure 9: Offers made to the first responder (left) and offers rejected (right) in the Traditional UG without (top) and with (bottom) ROFR 


\section{A3. Behavior of Second Responder (Traditional UG)}
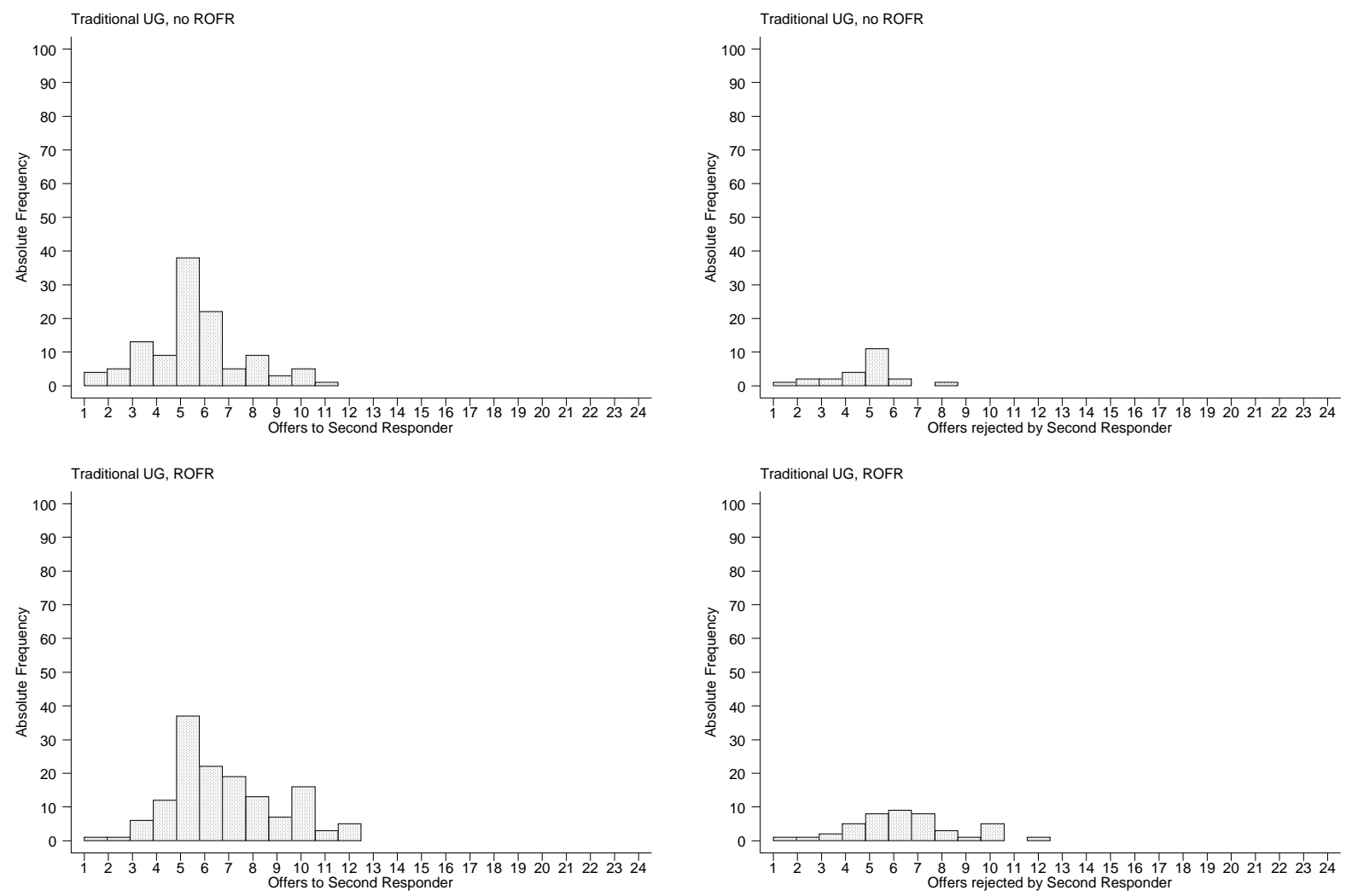

Figure 10: Offers made to the second responder (left) and offers rejected (right) in the Traditional UG without (top) and with (bottom) ROFR

\section{A4. Behavior of First Responder (Reverse UG)}
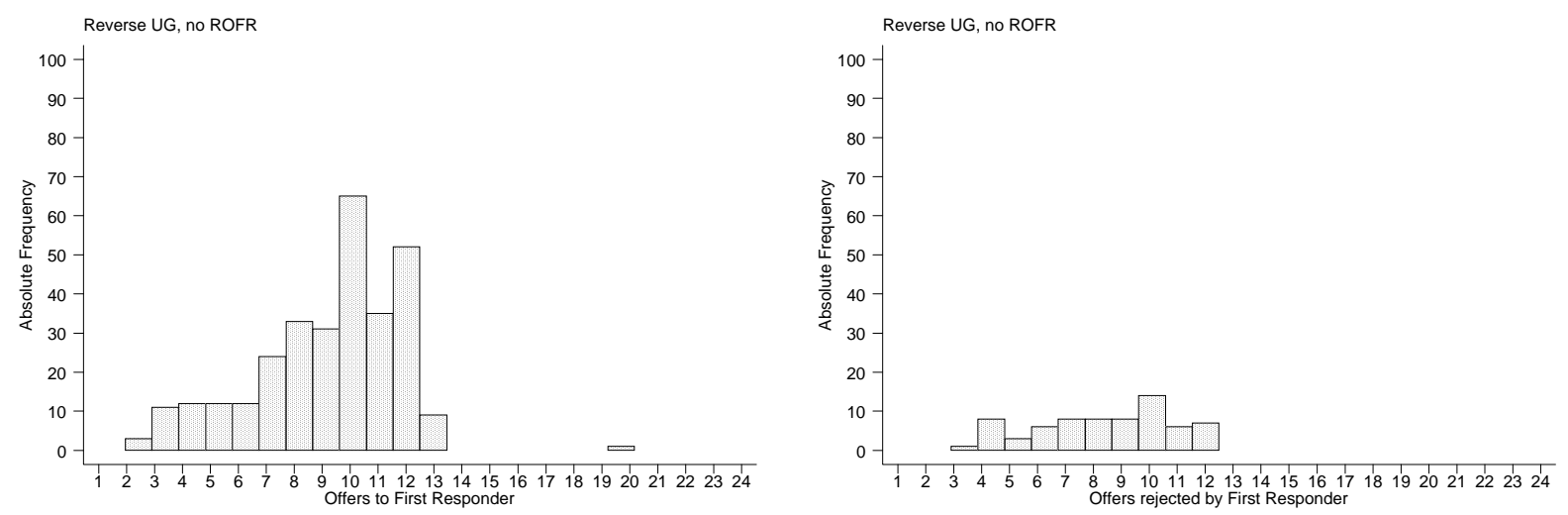

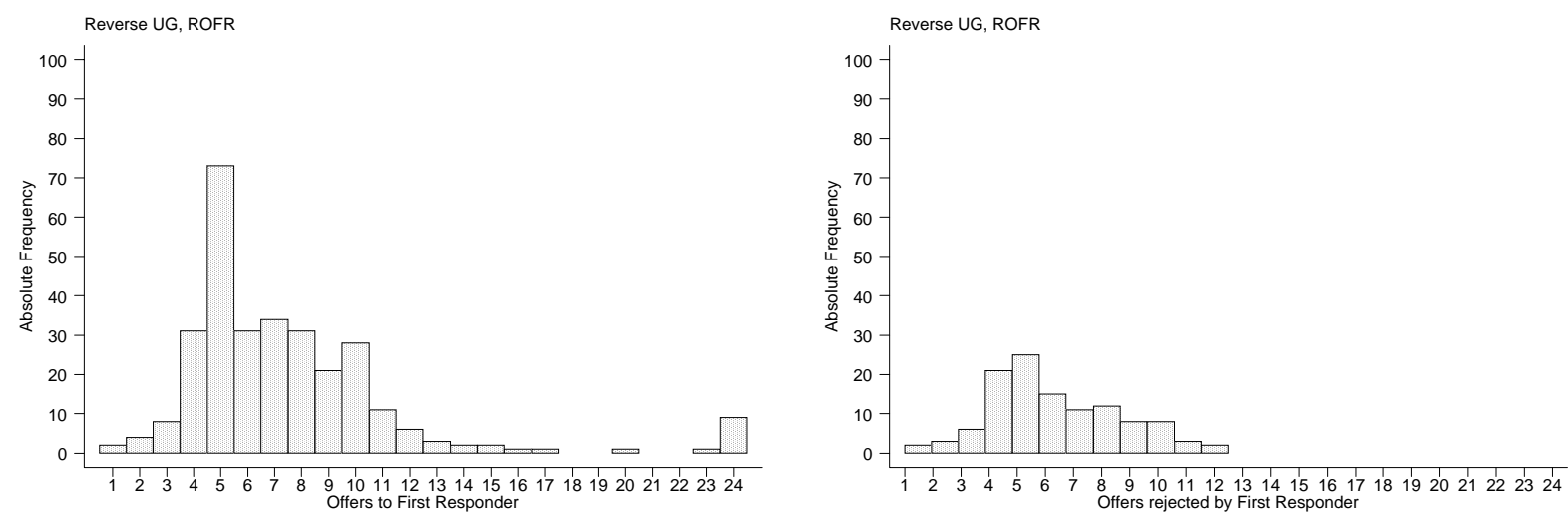

Figure 11: Offers made to the first responder (left) and offers rejected (right) in the Reverse UG without (top) and with (bottom) ROFR

\section{A5. Behavior of Second Responder (Reverse UG)}
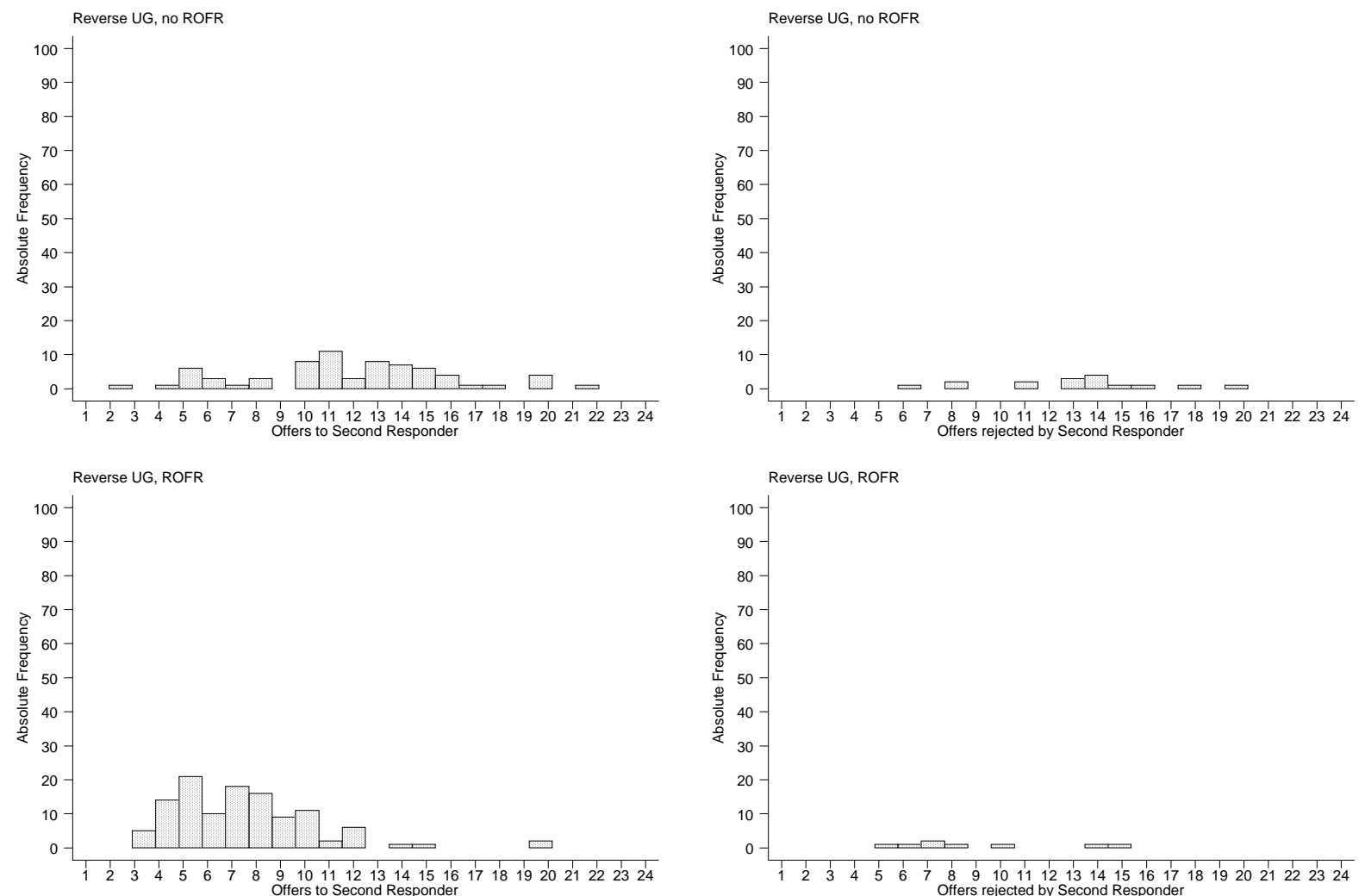

Figure 12: Offers made to the second responder (left) and offers rejected (right) in the Traditional UG without (top) and with (bottom) ROFR

\section{A6. Participation of Second Responder}

Figure 13 (A) shows that, after the initial periods, a second responder in the traditional UG gets to play roughly $40 \%$ of the time. Figure 13 (B) shows that the second responder gets to play less frequently over time in the reverse UG without the ROFR. The introduction of the ROFR changes the picture: the participation of the second responder remains roughly constant at $40 \%$ throughout. 

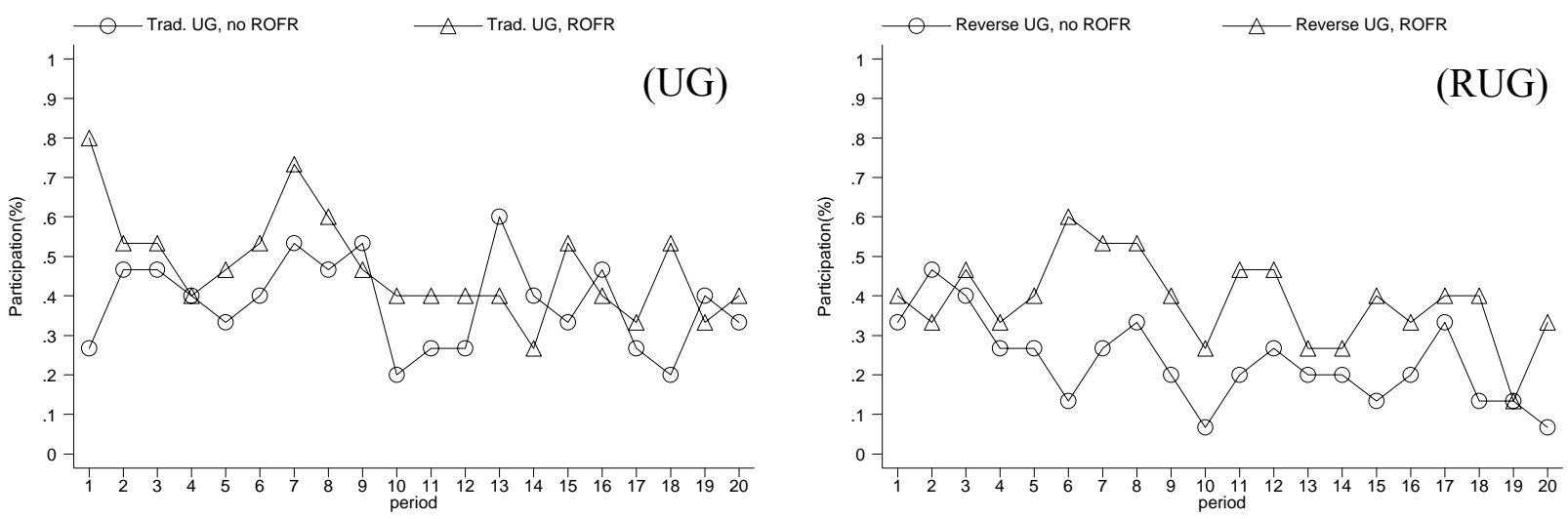

Figure 13: Observed frequency of participation of the second responder over time

\section{A7. Disagreement Behavior}

The number of disagreements in the reverse UG is significantly less than in the traditional UG (24 versus 67, $\grave{U}=2.14, p<0.05$. robust rank order on session level data). ${ }^{31}$ In the traditional UG these disagreements result from rejections of the "take-it-or-leave-it" offers made to the second responder. In the reverse UG these disagreements are the result of the proposer choosing to end the bargaining. There are seemingly less rejections in the traditional UG without the ROFR (23) than in the traditional UG with the ROFR (44), but this difference is not significant ( $\grave{U}=-0.92$, n.s., robust rank order on session level data). The reverse holds true for the reverse UG. Proposers decided to end the bargaining in $16(5.33 \%)$ out of the 300 observations without the ROFR, and only 8 (2.67\%) out of 300 when the ROFR was implemented, $\grave{U}=3.24, p<0.025$, robust rank order on session level data. Given our fixed-pie setup, we can analyze efficiency regarding the occurrences of disagreements. It seems as if the introduction of the ROFR enhances efficiency in the reverse UG, but decreases efficiency in the traditional UG.

We see from the left graph of Figure 14 that disagreements in the traditional UG without ROFR occur throughout the entire duration of the experiment. However, the right graph of Figure 14 shows that disagreements in the reverse UG without the ROFR are more common in earlier than in later rounds.

\footnotetext{
${ }^{31}$ Again, please note that we are aggregating over all rounds within one session. The numbers of rejections given are total rejections from all session within one treatment but robust rank order tests are done on session level data only.
} 

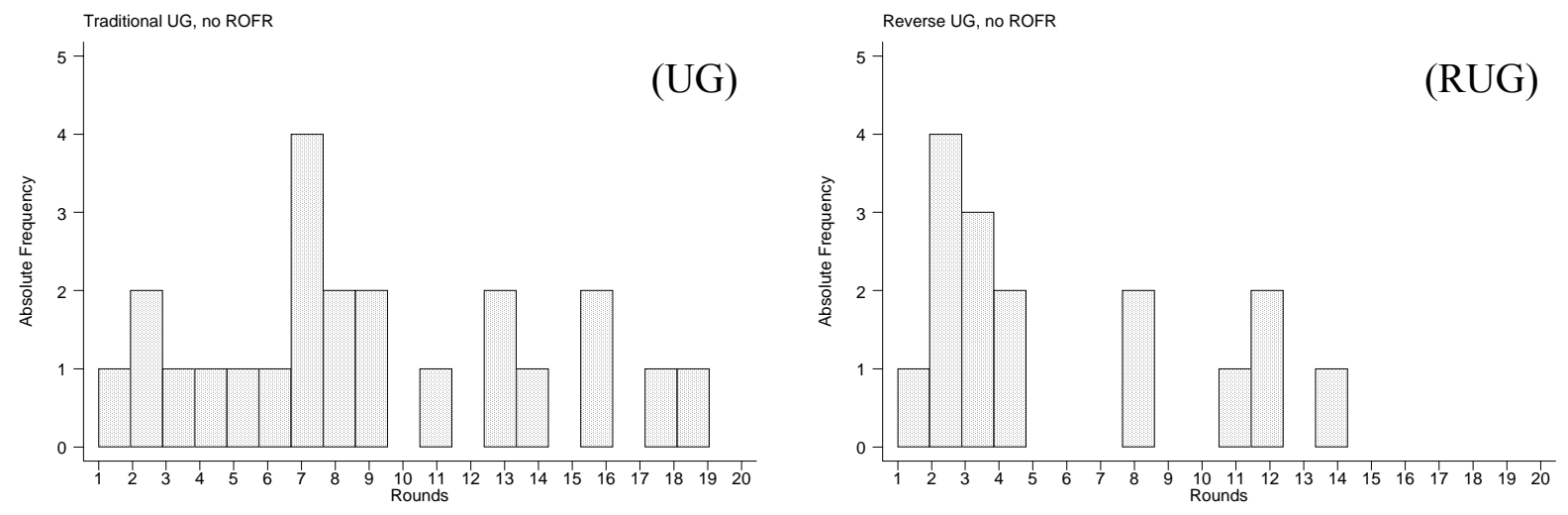

Figure 14: Histogram of disagreements for the UGs without ROFR over time 


\section{Appendix B}

\section{Instructions used in the reverse UG with ROFR}

Welcome to the Computer Lab for Experimental Research at the Harvard Business School. Thank you for agreeing to participate in this experimental investigation on economic behavior.

Please do not touch your computer until everyone is seated, and we have read the instructions together.

Subject Identification Number:

Date:

Please read along with me as I read the instructions. There will be opportunities to ask questions if the instructions are not clear.

The experiment consists of 20 periods. At the outset, all participants are assigned one of two roles. They are either a proposer or a responder. Responders are further divided into first and second responders. These roles remain constant throughout the entire duration of the experiment. In each period one proposer is randomly matched with two responders. The task in each period is to try to divide 25 points, using the following rules:

The proposer makes an offer to the first responder. This offer must be in the range from 1 point to 24 points. The first responder can accept or reject this offer. If the first responder accepts, the bargaining ends and the first period is over. The payoffs from that period are then such that the first responder receives the offer and the proposer receives the rest, 25 minus the offer. The second responder doesn't receive anything. If, however, the first responder rejects, the proposer can then (1) either make a new offer (which has to be higher than the last offer by at least one point) or (2) end the bargaining with the first responder and make an offer instead to the second responder. The second responder can then accept or reject the offer. If the second responder rejects, the proposer can make a new offer (which has to be higher than the last one by at least one point) or end the bargaining. If he ends the bargaining, the proposer and both responders do not 
get anything. If the proposer continues making offers and the second responder accepts and this offer is lower than the last rejected offer made to the first responder, the second responder gets the offer and the proposer receives the rest, 25 minus the offer. However, if the offer is higher (more generous) than the last rejected offer to the first responder, the first responder has the right of first refusal, which means that he is asked whether he would like to accept this new offer or not. If the first responder accepts, he receives the offer and the proposer receives the rest, 25 minus the offer. The second responder does not receive anything. If the first responder rejects, the second responder receives the offer and the proposer receives the rest, 25 minus the offer.

To summarize, if the second responder accepts an offer already rejected by the first responder, then the second responder receives the amount he accepted. Otherwise, i.e. if the second responder accepts an offer more generous than the last offer rejected by the first responder, then, the first responder has the right of first refusal. This means that the first responder can decide whether or not to accept this offer. If he accepts, he receives the amount accepted and the second responder doesn't receive anything, if he rejects, the second responder receives the amount accepted. Whenever an offer is accepted (regardless of who accepted it) the proposer gets 25 minus his offer. If the outcome of any period (out of 20) is a rejection then the proposer does not receive anything.

You will be informed on the computer screen whether you are a proposer, a first responder or a second responder. After each period you will be informed about your earnings in points of that period and the accumulated points up to that period. In each period proposers and responders will be randomly rematched.

You are being paid on performance based on a rate of 5 cents for every point. Please raise your hand if you have any questions regarding the instructions and the experiment. 
If you are a proposer you will see the following screen.

This number indicates in which period you are. In this example the experiment has just started.

Here you will see your offers and the corresponding responder's decision, either "pending", "rejected" or "accepted".

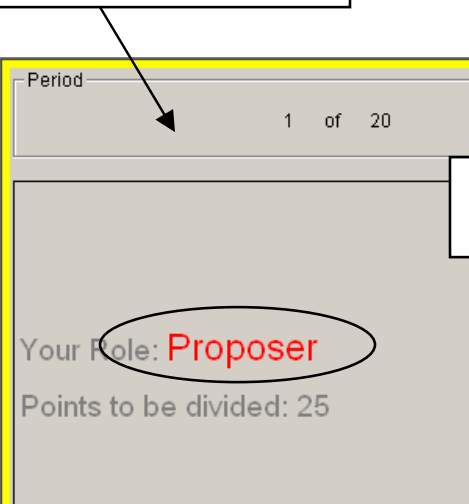

Here you will see the highest offer that the first responder rejected until now in this bargaining period.

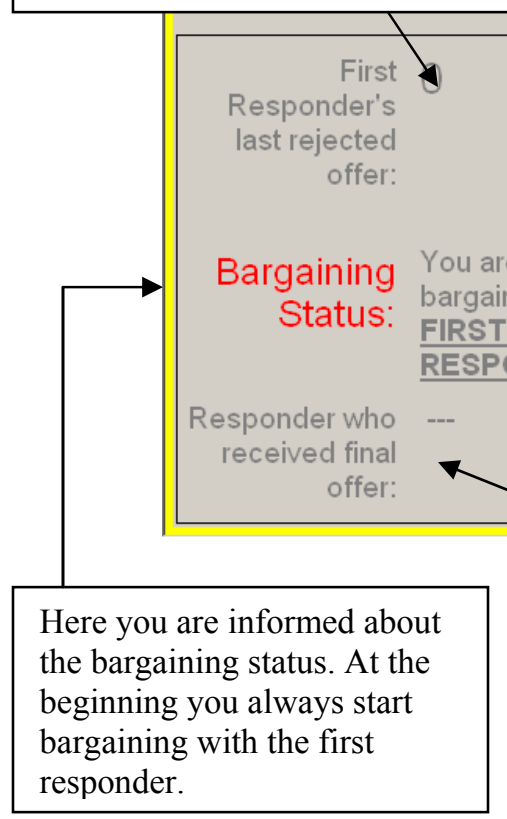

When the bargaining period is over, this will inform you about who accepted the final offer, either the first or the second responder.

After you have entered your offer, please press this button to submit your offer.

After you have made at least one offer you can decide to end the bargaining with either the first or the second responder by pressing this button. 
If you are a first responder you will see the following screen.

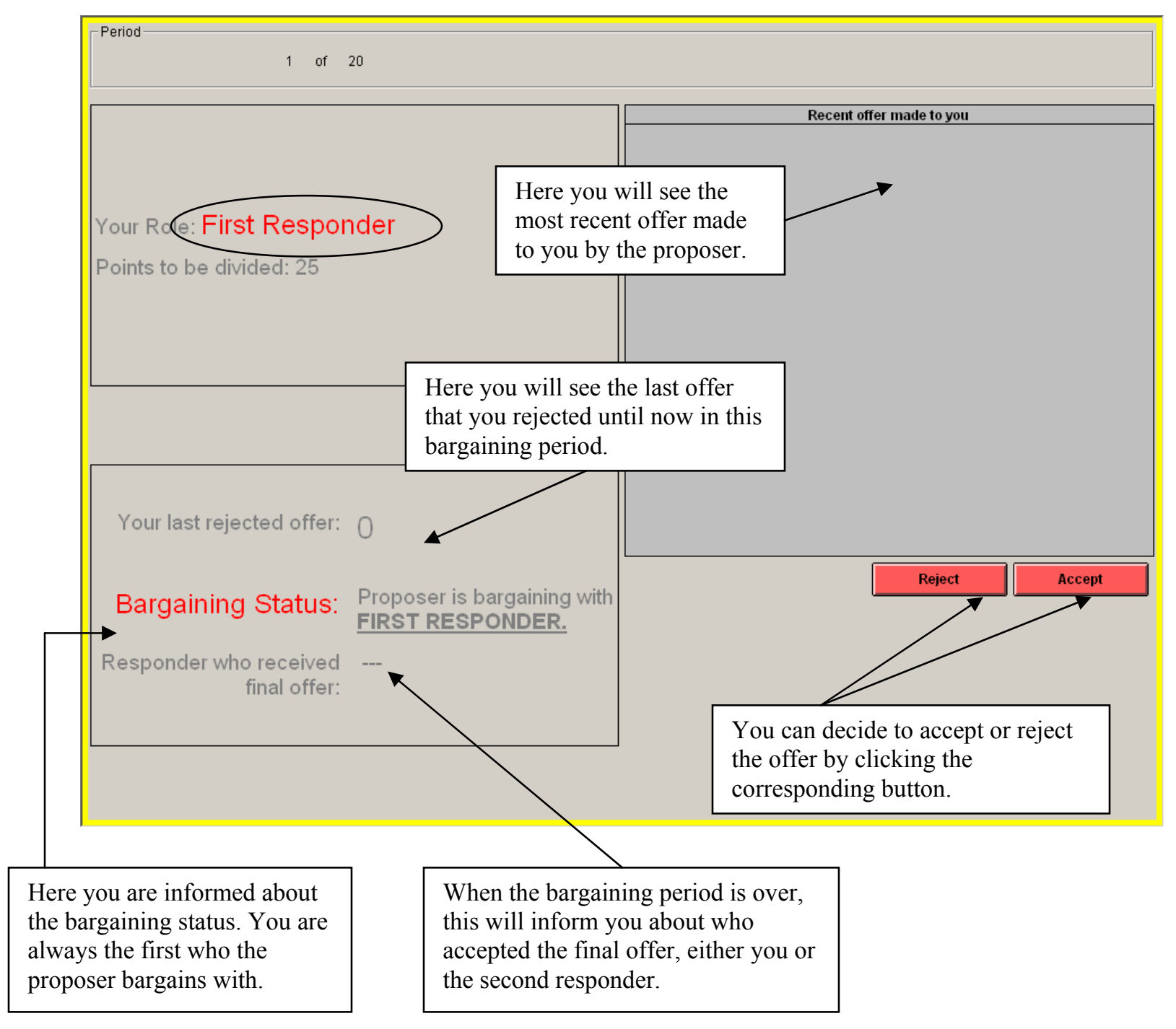


If you are a second responder you will see the following screen.

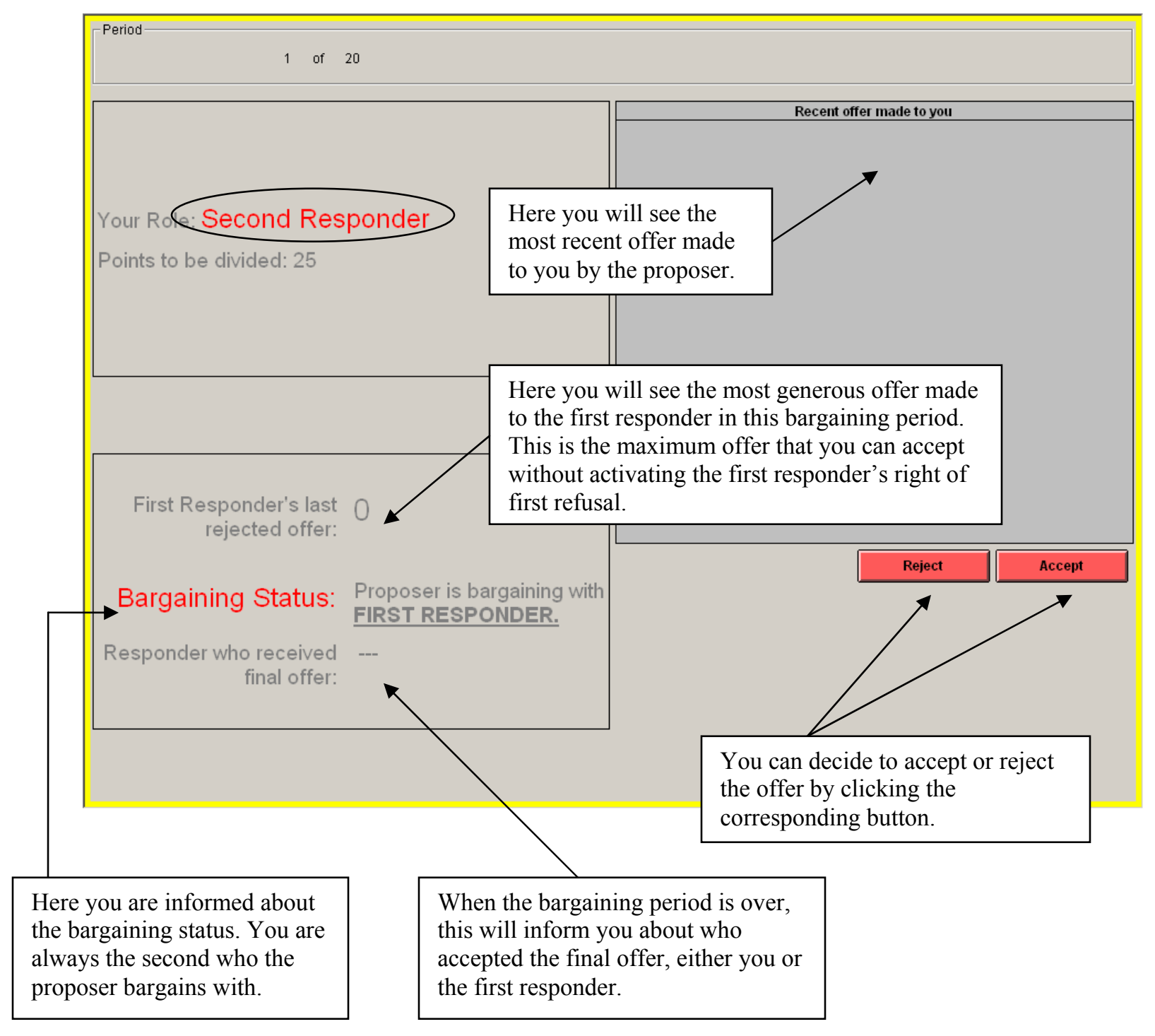

